\title{
Examining Provider-Patient Communication and Family Knowledge of Treatment in Pediatric Asthma Care
}

Thomas W. Ewell

twewell@mix.wvu.edu

Follow this and additional works at: https://researchrepository.wvu.edu/etd

Part of the Health Psychology Commons

\section{Recommended Citation}

Ewell, Thomas W., "Examining Provider-Patient Communication and Family Knowledge of Treatment in Pediatric Asthma Care" (2020). Graduate Theses, Dissertations, and Problem Reports. 7943.

https://researchrepository.wvu.edu/etd/7943

This Thesis is protected by copyright and/or related rights. It has been brought to you by the The Research Repository @ WVU with permission from the rights-holder(s). You are free to use this Thesis in any way that is permitted by the copyright and related rights legislation that applies to your use. For other uses you must obtain permission from the rights-holder(s) directly, unless additional rights are indicated by a Creative Commons license in the record and/ or on the work itself. This Thesis has been accepted for inclusion in WVU Graduate Theses, Dissertations, and Problem Reports collection by an authorized administrator of The Research Repository @ WVU. For more information, please contact researchrepository@mail.wvu.edu. 
Examining Provider-Patient Communication and Family Knowledge of Treatment in Pediatric Asthma Care

Thomas W. Ewell

Follow this and additional works at: https://researchrepository.wvu.edu/etd

Part of the Health Psychology Commons 
Examining Provider-Patient Communication and Family Knowledge of Treatment in Pediatric Asthma Care

Thomas W. Ewell, B.S.

\author{
Thesis Defense submitted \\ to the Eberly College of Arts and Sciences \\ at West Virginia University
}

in partial fulfillment of the requirements for the degree of

Master of Science in

Psychology

\author{
Christina L. Duncan, Ph.D., Chair \\ Cheryl Bodiford McNeil, Ph.D. \\ Nicholas Turiano, Ph.D. \\ Department of Psychology
}

\author{
Morgantown, West Virginia \\ 2020
}

Keywords: Provider-Patient Communication, Pediatrics, Asthma, Treatment Knowledge

Copyright 2020 Thomas W. Ewell 


\begin{abstract}
Examining Provider-Patient Communication and Family Knowledge of Treatment in Pediatric Asthma Care
\end{abstract}

Thomas W. Ewell

Asthma knowledge is an essential factor in being able to consistently and effectively manage asthma symptoms over time, which in turn reduces asthma morbidity and improves quality of life. The way in which certain provider factors, such as communication strategies or techniques, may differentially impact pediatric patients and their caregivers has little in the way of prior investigation. The current study involves a secondary analysis from a larger project. This larger study included 45 pediatric asthma patients (ages 8-17 years; $M=11.79$ ) and their primary caregiver recruited from pediatric asthma and allergy clinics within the WVU Medicine system to take part in a pilot randomized controlled trial (RCT) to evaluate the relative impact of two types of asthma action plans (AAPs), text-based or pictorial. The asthma action plan education session during their initial session in clinic was audiotaped, in which the asthma care provider described the child's prescribed asthma care plan. Patient and caregiver knowledge of the prescribed asthma care regimen was assessed separately via a structured interview immediately after asthma education. The overarching objective of this study was to evaluate the potential mediator role that provider, parent, and child communication plays in the effect of asthma education intervention type (i.e., type of AAP) on asthma treatment knowledge. While several significant correlations were found, none of the communication variables considered were found to either significantly predict asthma knowledge or mediate the relation between the type of AAP the patient received and AKI scores. These non-significant findings likely stem from limited variability and low frequency in key communication variables (e.g., family questions to provider, provider assessment of family understanding). However, child age, time since diagnosis, and having had a pictorial AAP were all significantly and positively correlated with child AKI scores. Future studies should engage a larger number of providers from a wider range of expertise and include communication training for providers and families when evaluating the utility of a pictorial AAP.

Key words: Provider-Patient Communication, Pediatrics, Asthma, Treatment Knowledge 


\section{Acknowledgements}

I would like to acknowledge Dr. Christina Duncan for her ongoing support and inspiration during this project and outside of it. Her patience and dedication to enriching my experiences over the course of this project is without compare.

I would also like to thank my committee members, Drs. Cheryl McNeil and Nicholas Turiano. Due in no small part to their considerable expertise, this project became something I'll be proud of for the foreseeable future.

Past and present members of the Pediatric Lab for Adherence and Transition at West Virginia University have had a significant impact on this project as well, and I would like to thank Dr. Lisa Hynes, Desiree Williford, Kristine Durkin, Corrine Ahrabi-Nejad, Jennifer Kelleher, and Cecelia Nelson for their continued support. Additionally, I'd like to thank Gabrielle Harrah, Destiny Noel, and Jenna Crouch for their work during data collection and analyses as undergraduate research assistants within the lab. This project could not have been possible without the entire lab's efforts on the wider Take Action for Asthma Control (TAAC) study.

I would like to thank the families that agreed to participate in the study for allowing myself and the other researchers in the lab to observe their care and gain perspective through their experiences. In addition, the clinic staff who facilitated data collection were essential to the process. Without their help, the challenges of in-clinic data collection would have been insurmountable.

Finally, I am so thankful for my family and friends over the course of this project. I can't begin to express how meaningful their support has been. 
Abstract............................................................ Page ii

Acknowledgements........................................... Page iii

List of Tables................................................ Page $v$

List of Figures................................................ Page vi

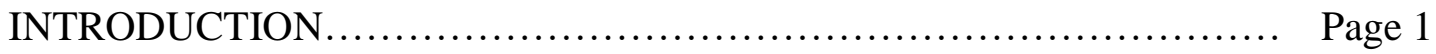

METHODS................................................... Page 13

RESULTS ..................................................... Page 21

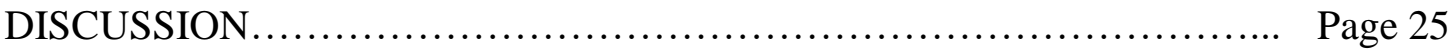

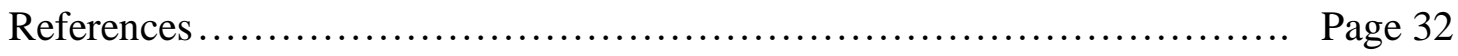


List of Tables

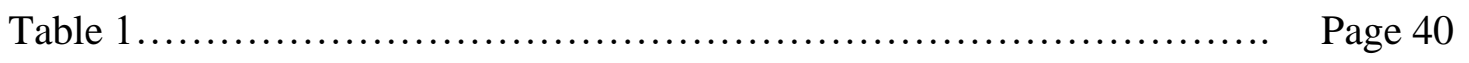

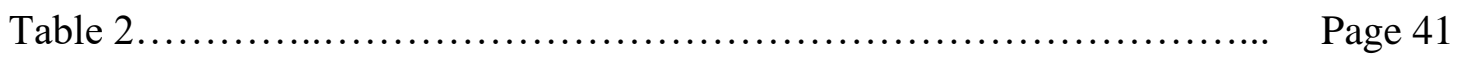






\section{List of Figures}

Figure 1: Example pictorial asthma action plan (PAAP) $\quad$ Page 44

$\begin{array}{ll}\text { Figure 2: Example written asthma action plan (WAAP) } & \text { Page } 45\end{array}$

Figure 3: Mediation model of the association between AAP group type, $\quad$ Page 46 parent and provider communication behaviors, and parent knowledge.

Figure 4: Mediation model of the association between AAP group type, $\quad$ Page 47 child and provider communication behaviors, and child knowledge. 
Examining Provider-Patient Communication and Family Knowledge of Treatment in Pediatric

\section{Asthma Care}

Asthma is one of the most common chronic illnesses found in children today, affecting roughly $8.3 \%$ of the U.S. population under 18 years of age (CDC, 2020). The breadth of symptoms individuals with asthma experience is considerable, although the most typical include daytime and nighttime cough, wheezing, chest tightness, and breathlessness (Globe et al., 2015). When taken together, the combination of symptoms can lead to significant impairment in children's daily functioning and can create notable fear and avoidance related to asthma triggers (e.g., exercise) that in turn can limit participation in activities they enjoy and need for appropriate development (Stewart et al., 2011). Care for persistent asthma typically involves two medications, an inhaled corticosteroid (sometimes in combination with a long-acting daily bronchodilator) as a daily preventer or controller medication, and a short-acting beta-agonist (SABA) as pre-exercise treatment and to address asthma symptom flares. Patients also are taught to avoid asthma triggers, such as allergens, smoke, strong smells, and cold air (Janssens \& Ritz, 2013). Consequently, education on asthma management is critical, with the end goal to optimize asthma management to in turn minimize impairment and symptom experience. This education requires a collaboration of the patient and their parents with providers in creating an agreed upon treatment plan, effectively discussing and understanding this treatment plan, and ultimately achieving good asthma control.

\section{Asthma Guidelines}

If good asthma control is the goal that providers strive for when rendering asthma care, then it follows that it should be readily definable and assessed. The concept of asthma control has some variability in its exact definition across the literature, and this variance is due in part to 
the existence of several different asthma care guidelines that providers may follow. Two of the most influential are the EPR-3 Guidelines on Asthma published by the National Heart, Lung, and Blood Institute (NHLBI) in the United States (NHLBI, 2012), and the Global Strategy for Asthma Management and Prevention guidelines used more widely across Europe (GINA, 2019). These guidelines have much in common, but differ in certain ways, such as the management and conceptualization of asthma symptom flare-ups (Okelo et al., 2013). A guideline that they have in common, however, is the recommendation of providing patients with a written asthma action plan (WAAP) to share information on how to manage daily medication, how to address asthma symptom flares, and what measures should be taken in the event of an emergency (see Figure 1). WAAPs are typically arranged as flow charts to communicate treatment information based on level of symptom exacerbation, with each stage including visual elements, such as stoplight colors and listing symptoms or warning signs to assist the reader in identifying the appropriate level of concern. Based on this assessment, the plan then dictates a suitable course of action to be followed. Despite WAAPs being considered a best practice and often serving as an efficacious educational tool (e.g., Waldecker et al., 2017; Yin et al., 2017), provider adherence to these guidelines varies dramatically, with some providers partially implementing them or applying them inconsistently within their clinical practice (Britto et al., 2013). In a national survey of currently practicing American Academy of Pediatrics members (Turner et al., 2009), providers who perceived their patients to have lower literacy levels were more likely to report difficulty in finding and using patient-education materials that were in an easy-to-read format. This led to an overall deficit in the provision of these materials to patients who would likely benefit from them the most (Turner et al., 2009). 


\section{WAAP Development and Concerns}

Current WAAPs fall into two schools of thought in regard to educating patients about detecting and responding to asthma flares. The first approach entails the use of a peak flow meter, with readings serving as a physiological measure of expiratory air flow from the lungs, which in turn informs treatment strategy (Bhogal, Zemek, \& Ducharme, 2007). The second approach uses symptom monitoring (e.g., cough, chest tightness) to index the individual's current asthma status and subsequent treatment strategy (Yin et al., 2013). Prior literature has consistently found both approaches to be efficacious, with limited or no differences observed between peak flow meter and symptom monitoring approaches (Adams et al., 2001; Letz, Schlie, \& Smits, 2004).

WAAPs increase treatment knowledge and reduce symptoms through effective education and skills training (Gibson \& Powell, 2004). Given their illustrated efficacy and inclusion within guideline-based asthma care, the expectation is that WAAPs would be implemented much more often than their actual prevalence data suggests (Ring et al., 2011). What likely accounts for a considerable part of this lower implementation are the challenging barriers that providers and families face. These can range from complex issues, such as differences between treatment guidelines and compatibility of WAAP formats with the provider's care ideology, to more practical issues like limited time available for providers to conduct asthma care education or lack of color printing in clinics, which can impact the integrity of a WAAP stoplight design (Mold et al., 2014). Partridge (2004) identifies several notable barriers to the consistent implementation of WAAPs by providers, including lack of awareness regarding treatment guidelines or recommendations and a perceived lack of time to provide these materials to patients. Regarding pediatric patients and their caregivers, a meta-analysis of the available literature found that when 
AAPs were implemented, there were several common themes that were predictive of continued AAP use. These themes included the family's conceptualization of asthma management as being chronic rather than in response to acute events and the quality of communication between providers, patients, and caregivers (Ring et al., 2011).

Health literacy also has been a key factor considered in how patients of any age are educated in their treatment plans. One avenue to overcome literacy concerns is the use of picturebased education to reduce the overall complexity of educational materials. Replacing words with pictures lowers the overall reading level necessary to fully comprehend content and increases clarity by reducing the use of jargon or other complicated medical terminology (Davis et al., 1996). There has been an identified need for the use of pictures in educational interventions for those with pediatric asthma (Waldecker et al., 2017). One such adaptation involves the development of a low-literacy WAAP that includes numerous techniques, such as color-coding and pictures to overcome the literacy barriers present among the pediatric asthma population (Yin et al., 2017).

As previously noted, WAAPs are a standard of care according to the treatment guidelines published by the NHLBI and GINA (NHLBI, 2007; GINA, 2019); however, their consistent implementation by providers and use by families has been thwarted by a variety of factors, including literacy demands. To address these concerns, a pictorial asthma action plan (PAAP) was developed that drastically limits the use of written text in favor of pictures and a color-coded layout (Hynes et al., 2019; see Figure 2 for sample PAAP). The PAAP serves to help children at various developmental levels, but also the adults in their lives (e.g. parents, relatives, coaches, teachers, etc.) who may have varying levels of health literacy. Indeed, this particular PAAP tool 
was developed with Appalachian families, a population where health literacy concerns have been previously observed (Denham et al., 2004; Ludke et al., 2006).

\section{Asthma Knowledge and Provider Education}

It is essential for asthma education interventions to target and effectively educate both patients and their caregivers to encourage better adherence to treatment plans and to ultimately optimize positive health outcomes (Silva \& Barros, 2013). Caregivers and their children often times have specific roles in managing asthma that evolve and change as the child ages and the process of transferring responsibilities from the caregiver to the child occurs. For instance, it may not be developmentally appropriate for very young children with asthma to be expected to take their bronchodilator and follow other necessary treatments without significant oversight and support from their caregiver. In contrast, older children and adolescents have varying degrees of independence and responsibility with regard to their asthma management (Horner \& Brown, 2015). As such, it is important to examine different factors that lead to effective education of pediatric patients and their caregivers. When providing developmentally sensitive asthma education, providers are more likely to facilitate effective asthma management, especially in targeting specific knowledge gaps or deficits that may be present (McMullen et al., 2007).

Consequently, understanding the process through which asthma treatment knowledge is typically acquired for parents and their children is essential. Not surprisingly, a considerable amount of knowledge for families is gained through provider interactions and instruction during routine clinic appointments (Hynes et al., 2015). Therefore, regular clinic attendance and effective communication between providers, patients, and caregivers is a crucial step in families understanding the child's asthma care plan. Sleath and colleagues (2012) illustrated how relatively simple communication strategies in asthma care guidelines, such as asking for 
caregiver or child input into the treatment plan, resulted in significantly higher medication adherence at follow-up. Likewise, asthma-related questions posed by providers to pediatric patients were correlated with higher reported asthma management self-efficacy and asthmarelated quality of life (Carpenter et al., 2013). Thus, there is substantial need for providers to effectively engage their pediatric patients, with previous studies linking asthma education given by providers to lower asthma morbidity days and decreased use of emergency services for exacerbations (Cabana et al., 2014).

Asthma providers often address pediatric patients and their caregivers in different ways, which can be an important communication strategy when it is developmentally appropriate. This does not necessarily mean, however, that pediatric patients and their caregivers have equal opportunity to provide feedback on their treatment plans. Sleath et al. (2011) found that, in 296 encounters between pediatric asthma providers and their patients, providers solicited child input on care in only $6 \%$ of encounters versus caregiver input in $10 \%$ of encounters. Similarly, they found that children asked one or more questions related to care in $13 \%$ of encounters, compared to caregivers asking in $33 \%$ of encounters (Sleath et al., 2011). A potential explanation for this difference is that providers are more readily engaging caregivers in asthma management but have difficulty involving their pediatric patients in the same fashion, which poses a notable challenge in fostering patient engagement in care, consistent with national guidelines (Carpenter et al., 2013).

Perhaps unsurprisingly, given these differences in engagement during asthma care education, children and parents exhibit differential levels of knowledge in regard to treatment (Butz et al., 2005). With young children, parents tend to be more knowledgeable than their children in regard to the child's treatment plan and are more reliable reporters of symptomology 
(Silva et al., 2015). This relation shifts, however, in adolescence, when youth become more reliable reporters of their own symptoms (Silva et al., 2015). In a study evaluating the implementation of an asthma education program for rural youths and their caregivers, Butz and colleagues (Butz et al., 2005) found a relatively weak correlation between parent and child asthma knowledge. It is unclear whether this finding was due to the intervention type, given that parents' knowledge in the intervention group was significantly higher than their control counterparts versus no significant difference in the child group at baseline, or a prevailing feature in the population (Butz et al., 2005). Addressing these differences in knowledge between parents and their children subsequently becomes an important avenue of research. By better understanding how to engage younger children in their asthma care and encourage learning, we can potentially narrow this knowledge gap.

\section{Patient-Provider Communication}

The dual role that providers serve in fulfilling their patients' need for care and education on their condition poses its own unique challenges. This difficult task is then complicated when commonly observed limitations in clinic, such as time, resources, or availability of clinic staff, are taken into consideration. One study (Turner et al., 2009), which surveyed 900 members of the American Academy of Pediatrics nationally, examined pediatric provider self-report of experiences with health literacy, use of communication techniques, and barriers to communication during clinic visits. While almost all providers surveyed indicated that they regularly engaged in basic communication strategies, such as using everyday language to describe medical information, significantly fewer providers indicated that they used enhanced communication techniques at least $50 \%$ of the time (Turner et al., 2009). These enhanced communication techniques included strategies like indicating key points on written educational 
materials. Providers noted that some of the most common barriers they experienced when communicating effectively with patients and families were time limitations, as well as the volume and complexity of the information needing to be conveyed (Turner et al., 2009). Nonetheless, using enhanced communication techniques early in treatment has been positively related to appropriate asthma medication device technique at 1-month follow up in a study of provider communication styles with youth during routine care visits (Sleath et al., 2012). These communication strategies included questions posed by the provider, demonstration of device technique, and having the patient demonstrate device technique as practice. In this particular study (Sleath et al., 2012), a potential limitation is the original referral source for services, as some participants may have been referred specifically for asthma education, on the basis of chronic non-adherence or new diagnosis, versus specialist care for severe or complicated disease. This approach could result in sampling bias, wherein the participant groups may differ substantially at baseline on level of adherence or asthma severity, which could subsequently inflate the observed difference in device technique.

Provider communication is further complicated in the context of caring for pediatric patients because the provider must communicate treatment information to both patients and their caregivers, each of which likely have different cognitive skills as well as responsibilities for disease care. Depending on patient characteristics (e.g., age, maturity), the balance of responsibility between the child and their caregiver can be dramatically different (Sonney, Segrin, \& Kolstad, 2019). Another consideration is the collaboration that occurs between pediatric patients and their caregivers. The nature of this collaboration and the responsibilities each person carries often vary from family to family and child to child depending on factors such as age, illness severity, and so on (Horner \& Brown, 2015). On average, children spend less time 
with their parents as they grow older, and so children take on more day-to-day tasks and decision-making power around asthma management (McQuaid et al., 2007). Similarly, as children age, they develop greater understanding of their illness and its impact on their daily life, as well as the treatments required to effectively manage their symptoms (Barton et al., 2002). Another trend to note, younger patients are often less reliable reporters of their symptoms and treatment adherence than their parents, which later changes to adolescents and young adults being more reliable than their parents (Petsios et al., 2011). This shift can likely be attributed in part to the growth in child independence and responsibility over time (Hedman et al., 2005).

As a result of these considerable differences observed across the pediatric population due to age, developmental level, and family division of responsibility for asthma care, there is a great need to develop education tools that can effectively reach all pediatric patients and their caregivers at their level of need. In doing so, these education tools become more versatile and better able to affect meaningful improvement among the desired asthma management domains, be it treatment knowledge, adherence, understanding of symptoms, or otherwise (Britto et al., 2014). Indeed, sharing relevant education with each family member is a crucial part of ensuring that the patient's asthma care routine is carried out regularly and correctly. Moreover, the quality and type of these provider-patient interactions has been linked to healthcare disparities observed in racial and ethnic minority groups (Valenzuela \& Smith, 2016). Rural populations also experience notable healthcare disparities that often stem from certain cultural factors or views surrounding medical care, as well as financial burden and geographic barriers, which share some commonality with other underserved populations (Douthit et al., 2020). As a result, it is especially important to better understand provider communication with families who experience these disparities. 
Previous research relating to patient-provider communication has likewise been variable, with a range of quantitative and qualitative methodologies employed to characterize what constitutes sufficient versus poor communication. Ha and Longnecker (2015) conducted a review of the literature on patient-provider communication and identified a series of different indices that impact the quality of communication and subsequently the influence it has on the patients' ability to follow directions given by their provider, adhere to their prescribed treatment, and perceive a sense of control in regard to their illness. These indices include communication skills, communication training, collaborative communication, conflict management, and health beliefs (Ha \& Longnecker, 2015). Collaborative communication, or the opportunity for a reciprocal relationship in which both the provider and the patient have input on decision making and exchange information as it relates to care, is an essential component in developing a meaningful therapeutic relationship (Ha \& Longnecker, 2015; Moss et al., 2016). Based on prior literature and current guidelines, the role of collaborative communication in developing treatment plans, such as AAPs, makes this an important point of research.

Engaging children and adolescents in asthma education can be very difficult for providers for several reasons. One of the most pertinent is that children are not always care-seeking of their own volition; rather, their parents typically identify the need and seek services. Furthermore, certain stigma exists among youths in regard to having asthma, and they may prefer to act as if they do not have the illness, which can subsequently lead to withdrawal from care providers (Ahmad \& Ismail, 2015). Engagement with pediatric patients is often challenging as a result of the noted barriers and other, more pragmatic barriers like distractions in the clinic environment. As a result, higher-level engagement with patients in routine care is infrequent and may contribute to outcomes, although further evidence in the literature is needed (Bombard et al., 
2018). Given varied levels of responsibility that pediatric patients experience regarding asthma management, provider-patient interactions (PPIs) need to be tailored to children across a range of ages and developmental levels. The bidirectional nature of PPI further contributes to this challenge, where patients and providers are equally responsible for the quality and type of interactions that occur. It seems that AAPs can serve as a PPI tool to effectively structure asthma education to include caregiver and child input, provider sharing of information, and opportunity for questions to be asked and addressed.

\section{Summary}

Pediatric asthma care and management is a function of numerous variables, including provider-patient communication, asthma treatment knowledge on the part of the child and caregivers, and patient engagement, for which many of the relations are currently not very wellstudied in the literature. As part of guideline-based care, asthma providers educate patients and their families regarding the management of asthma symptoms and develop treatment plans, ideally in collaboration. Children of different ages with a range of developmental skills may require different levels of education or support from their providers and caregivers, which may require providers to alter the ways in which they communicate with patients as well. This identified need for collaboration in effective asthma management between patients and their providers means that communication is an essential aspect of rendering care and fostering knowledge regarding asthma in pediatric patients and their families. That being said, the relation between provider-patient communication and asthma treatment knowledge is not currently understood very well and there is an identified need to understand how parents and children learn from their providers (Peterson-Sweeney et al., 2003). To address these gaps in the literature, the current study seeks to evaluate how asthma treatment knowledge may be differentially obtained 
by caregivers and their children during routine asthma care visits, as well as the potential mediator role that provider-patient communication plays in the type of AAP education tool predicting parent and child knowledge of the child's asthma care routine.

\section{Specific Aims}

Aim 1. The first aim of this study was to evaluate the extent to which provider, parent, and child communication behavior (e.g., \# of questions asked) predicts parent and child knowledge of the child's prescribed asthma care regimen. The following models were tested:

a. Provider communication behaviors predicting parent knowledge (1A)

b. Provider communication behaviors predicting child knowledge (1B)

c. Parent communication behaviors predicting parent knowledge (1C)

d. Child communication behaviors predicting child knowledge (1D)

e. Provider \& parent communication behaviors $(1 \mathrm{~A}+1 \mathrm{C})$ predicting parent knowledge

f. Provider \& child communication behaviors $(1 \mathrm{~B}+1 \mathrm{D})$ predicting child knowledge

Based on the findings of Sleath et al. (2011), it was hypothesized that more effective provider communication behaviors (e.g., assessing family understanding with questions) would be associated with greater parent and child knowledge (Diette et al., 2007). Similarly, the observations found within Carpenter et al. (2013) led us to hypothesize that greater parent communication (e.g., more questions asked) would be predictive of higher knowledge scores, while greater child communication (e.g., proportion of words spoken by the child during asthma education relative to parent) would be predictive of higher child knowledge scores. 
Aim 2. The second aim was to conduct a parallel mediation analysis to evaluate the potential role of communication variables as mediators in how type of AAP given to a family predicts parent or child knowledge of the child's asthma care regimen. The following models were tested:

- $\quad$ Mediation Model A: Type of AAP $\rightarrow$ Provider Communication (toward parent) \& Parent Communication $\rightarrow$ Parent Knowledge

- $\quad$ Mediation Model B: Type of AAP $\rightarrow$ Provider Communication (toward child) \& Child Communication $\rightarrow$ Child Knowledge

Based on the limited literature available in other populations (Patel et al., 2012), it was hypothesized that using a PAAP would serve to simplify education so that (a) providers can more effectively and efficiently communicate and discuss the child's asthma care regimen, and (b) families, regardless of literacy levels, would more readily engage in asthma care education discussions. Subsequently, it was hypothesized that type of PAAP would significant predict treatment knowledge for parents and their children respectively, with communication variables serving as mediators in this relation. In particular, it was expected that PAAP would predict greater communication, which in turn would predict higher asthma treatment knowledge scores for parents and children.

\section{Method}

\section{Participants}

The sample included 45 pediatric asthma patients, ages 8-17 years $(M=11.79 ; S D=$ 2.75) and one of their primary caregivers who took part in a larger, grant-funded, 2-arm, pilot RCT [Take Action for Asthma Control (TAAC) project]. The TAAC RCT measured the relative impact of two types of AAPs (written/WAAP vs. pictorial/PAAP) across 6 months (Hynes et al., 2019). The race of our sample was predominantly White (93.3\% White, $2.2 \%$ Hispanic/Latino, 
2.2\% Mixed Race, 2.2\% Missing/Did not respond). The sample, while exhibiting limited racial/ethnic diversity, was consistent with the West Virginia population according to the most recent U.S. Census data available (U.S. Census Bureau, 2019). Participants attending the clinics in which recruitment occurred were seeking specialty care, and many travelled notable distances from across rural West Virginia and even other states. Participants were diagnosed with persistent asthma by their physician and prescribed daily controller medication (i.e., inhaled corticosteroid; ICS) as an inhaler. Patients were either newly diagnosed with persistent asthma (n =6) or had an established diagnosis but were in need of a new treatment plan due to suboptimal symptom control $(\mathrm{n}=39)$. To be included in the study, participants had to have no history of having received a written asthma action plan. Patients with significant cognitive impairment, who were not be able to complete the required study measures even with support from caregivers and researchers, were excluded from the study. Hynes et al. (2019) provides more information regarding the nature of the previous study and data collection. Please refer to Table 1 for additional participant demographic information.

\section{Procedure}

Investigators received approval from the Institutional Review Board at West Virginia University to collaborate with asthma care providers in their clinics to recruit participants and collect data. Participants meeting eligibility criteria were recruited during routine appointments from pediatric asthma and allergy clinics within the West Virginia University Medicine system. Data for the study were previously collected during the first session of the aforementioned larger project. During this appointment, the asthma care provider briefly introduced the study. If families expressed interest, they were then introduced to research staff who fully described the 
study procedures and time commitment. Consent and assent were obtained from the caregiver and pediatric patient, respectively, following this description of the study.

Two asthma care providers took part in this study, one a pediatric allergist (for 33 participants) and the other a pediatric pulmonologist (for 12 participants). Once enrolled, participants were randomized to receive either a WAAP or a PAAP via a stratified randomization procedure, controlling for age and physician-diagnosed asthma severity (mild persistent, moderate persistent, or severe persistent). Asthma care providers generated the participant's personalized WAAP or PAAP, encompassing the patient's individualized, prescribed asthma treatment plan (e.g., medication, actions to take in an emergency, pre-exercise routine). Per standard care, providers reviewed the child's AAP with families. Although providers were encouraged to cover all aspects of the AAP and to give families the opportunity to ask questions regarding the child's asthma care plan, no further guidance was given on conducting the AAP education session. Researchers were not present in the examination room during these AAP education sessions; rather, sessions were audio recorded and later transcribed for analysis.

Participants and their caregivers were each given several questionnaires, including measures examining family division of asthma care responsibility, health literacy and other constructs that go beyond the scope of the current study. Moreover, spirometry (i.e., lung function testing) and electronic monitoring of adherence were part of study procedures for the larger project but were not a focus of this particular study. Measures that were dependent upon the participant's AAP, such as the Asthma Knowledge Interview (Appendix B), were administered following the AAP education session. Both participants and their caregivers each received a gift card worth $\$ 30$ for enrolling in the study, and this compensation was not dependent upon completion of measures. 


\section{Data Sources}

Participant Information Form (PIF) (Appendix A). The Participant Information Form (PIF) was created to collect child and family demographic information from caregivers. The PIF includes items pertaining to the participant's age, gender, ethnicity, grade in school, place of residence, and history of medical illness or special education, as well as information regarding the caregiver and other family members present in the home. The project used information from the PIF to describe the sample characteristics and to examine sociodemographic variables for relevant analyses.

Asthma Knowledge Interview (AKI; Parent and Child Forms) (Appendix B). The Asthma Knowledge Interview was designed for the purpose of the larger grant project. It has 2 sections relating to knowledge of the child's prescribed asthma action plan. The interview was administered to children and caregivers separately. Minimal differences exist between the parent and child forms; these differences consist solely of modified verbiage to reference the informant ("Your child" vs. "You"). Respondents were provided with a copy of their AAP to reference at their discretion during the AKI.

Zone Identification. The first section consists of 7 items presenting a situation (e.g., sports practice) and corresponding symptoms (e.g., shortness of breath) for a hypothetical child and then asks the respondent to indicate what zone (Green, Yellow, Red) characterizes the child's symptom profile. These items are scored as correct (1) or incorrect (0). There is one additional item (\# 8) in this section that asks whether the participant child regularly takes part in physical activities that require the use of pre-exercise albuterol inhaler dosing; however, it is not scored. Item 5 was excluded from scoring because it refers to allergies as an asthma trigger; not 
all participants experience allergies, making it not applicable across all participants. Thus, the score from this section is comprised of items 1-4 and 6-7, with a total possible range of 0-6.

Regimen Recall by Zone. The second section is comprised of 3 items that ask the respondent to describe the child's prescribed treatment plan for green, yellow, and red zones, respectively. Given that these responses are open-ended in nature, responses are scored on a scale of $0-2$, based on their quality with regard to the fidelity to the participant's AAP by zone. Specifically, an item is scored as 0 when the participant's response is incorrect or inconsistent with their treatment plan, 1 if the response is partially correct but incomplete or vague, 2 when the response is mostly correct but is still missing some detail, and 3 when the response includes all accurate treatment details. Thus, the total possible range of scores for this section is 0-9. Again, because the responses are qualitatively scored, two coders independently scored responses for $20 \%$ of the sample, stratified by AAP group. To establish interrater reliability, a codebook was developed with rules to guide coders through ambiguous or complex responses. Coders analyzed a small sample $(n=4)$ of participants' responses and instances of disagreement were discussed and subsequent modifications to the codebook were made as needed. Then, the coders independently rated $20 \%$ of the sample of participants $(n=9)$, excluding those on which the initial codebook was developed. Interrater reliability was calculated for each item using freemarginal Kappa, with a set-point of 0.70 as the cutoff for satisfactory reliability (McHugh, 2012). Overall, interrater reliability was within acceptable margins for parent green, yellow, and red zone codes $($ Percent Agreement $=96.15 \%, 80.77 \%, 88.46 \% \&$ Kappa $=0.95,0.74,0.85$, respectively) and child green, yellow, and red zone codes (Percent Agreement $=96.15 \%, 100 \%$, $84.62 \%$ \& Kappa $=0.95,1.00,0.79$, respectively) 
Total Score. Analyses used a total score across both sections, which was generated separately for children and caregivers. The total possible range is 0 to 15 . Cronbach's alpha for the 9-item AKI measure was .52 for parent version and .68 for child version.

AAP Education Session Recording. The AAP education session recording was coded using a framework designed in a previous study that investigated provider communication and its relation to parent and child recall of asthma treatment plan details (Duncan, Tanner, Mentrikoski, Wilson, \& Hogan, 2012). This framework produces frequency data relating to parent and child questions to the provider, as well as directive statements or questions issued by providers to the parent or child. In addition to these variables, the proportion of word count by parent, child, and provider to total word count in the education session transcript will be calculated. See Table 2 for communication behavior codes and code definitions.

Coding reliability. Audio recordings of AAP education sessions were coded by a primary coder, and reliability coding was completed by a second, independent coder for $30 \%$ of randomly selected participants. Both coders were uninformed as to the group (type of AAP) assignment for each participant, unless it was stated during the conversation captured in the transcript. To ensure consistency across coders, a codebook was developed that includes definitions for each of the communication behavior variables within the coding system (as displayed in Table 2), as well as differential rules for coding under uncertain conditions (questions posed by the provider with an unclear target, etc.). Coders were trained by reviewing the codebook and applying the coding system to example audio recordings taken from a previous study in which the foundation of the behavioral coding system was developed. Each coder coded identical audio recording transcripts during training, and then results were reviewed by the research team. Disagreement between coders was resolved via review by coders in consultation 
with the primary investigator, until consensus was reached. Reliability was assessed for each of the communication behavior variables via Pearson correlation coefficient. Coders were considered to be reliable when a Pearson correlation coefficient was greater than or equal to 0.8 (McHugh, 2012). Following establishment of reliability between coders on all codes on training transcripts, the study transcripts were coded in four batches with reliability calculated for each batch before proceeding to the next set of transcripts. If the correlation coefficient was less than 0.80 for one or more variables, coders discussed discrepancies, along with the primary investigator, and subsequently coded sets of 3-4 practice transcripts until reliability $(r \geq 0.80)$ was re-established before recoding the set of transcripts in which disagreement was observed and moving forward with any additional transcripts to code. Pearson correlation coefficients were within the acceptable range for provider questions to parent $(r(14)=1.00)$, provider questions to child $(r(14)=.96)$, parent question to provider $(r(14)=1.00)$, child question to provider $(r(14)=$ 1.00), provider directive statement to parent $(r(14)=.98)$, and provider directive statement to child $(r(14)=.98)$.

\section{Analyses}

\section{Preliminary Analyses}

Statistical analyses were conducted using Statistical Package for the Social Sciences (SPSS 21). Participants with any missing responses on the items used to generate total AAP Knowledge Interview scores were excluded from analyses. Data were inspected to determine skew, kurtosis, or the presence of outliers to ensure normality; corrections were applied as appropriate. Analyses were run with and without identified outliers to evaluate their impact on the findings. Additionally, particular focus was given to the counts obtained for all frequency communication variables. Where variables had low to no frequency (e.g., provider questions to 
child), variables were combined (e.g., provider questions to family in total, regardless of targeting child or parent) and analyses adjusted accordingly. Descriptive statistics were calculated for sociodemographic variables from the PIF and for all study variables. An initial correlation table was generated for the AAP Knowledge Interview total scores (parent \& child) with some key demographic and medical variables (as possible covariates) and with each of the communication behavior codes.

\section{$\operatorname{Aim} 1$}

In the first aim, we sought to examine provider, parent, and child communication behaviors as predictors of parent and child knowledge of the child's asthma care regimen. A multiple regression analysis (multiple predictors) or linear regression (single predictor) was then conducted for the following models:

- (1A) Provider communication with parent (ProvQP, ProvDirP ${ }^{a}$ ) predicting total parent knowledge score;

- (1B) Provider communication with child (ProvQC, ProvDirC ${ }^{a}$ ) predicting total child knowledge score;

- (1C) Parent communication with provider (ParentQProv) predicting total parent knowledge score;

- (1D) Child communication with provider (ChildQProv) predicting total child knowledge score;

- $\quad(1 \mathrm{~A}+1 \mathrm{C})$ Provider and parent communication (ProvQP, ParentQProv, ProvDirPa $)$ predicting total parent knowledge score; and

- $\quad(1 \mathrm{~B}+1 \mathrm{D})$ Provider and child communication (ProvQC, ChildQProv, ProvDirC ${ }^{\mathrm{a}}$ ) predicting total child knowledge score. 
Potential covariates (i.e., child age, time since asthma diagnosis, type of AAP) were assessed and, if significantly correlated with the relevant AKI score variable, included in each of the regression models.

\section{$\operatorname{Aim} 2$}

In the second aim, we sought to test communication variables as possible multiple mediators on the relation between AAP type and knowledge of asthma care regimen. Using the PROCESS macro developed by Hayes (2012), mediation analyses were conducted. The first mediation analysis (2A) tested provider communication behavior codes directed towards parents and parent communication behavior codes as mediation in the association between AAP type and parent knowledge of asthma care regimen. A second mediation analysis (2B) was conducted to test provider communication behavior codes directed towards the child and child communication behavior codes as mediation in the association between AAP type and child knowledge of asthma care regimen. Within each analysis, variables were entered simultaneously. When significantly correlated with parent or child AKI total scores, demographic and medical variables (e.g., child age \& time since asthma diagnosis) were entered within each model as covariates.

\section{Results}

\section{Preliminary Analyses}

Of the 45 participants, four were excluded from analyses as the result of a modification to the Asthma Knowledge Interview (AKI) early in data collection, which produced missing data. With the exception of these instances, no missing data were observed. Skew and kurtosis were visually inspected and found to be within acceptable margins for each of the study's frequency variables. A few variables (i.e., provider directive statements posed to parent; parent questions posed to provider) had instances of frequency that were notably higher than the variable mean, 
but these values were consistent across the variables being measured for that participant and thus were not considered to be outliers.

\section{Descriptive Statistics}

Several study communication variables had a notably low frequency, including parent questions posed to provider $(M=0.67, S D=1.52)$, child questions posed to provider $(M=0.24$, $S D=1.09)$, provider assessment of parent understanding $(M=0.07, S D=0.330)$, and provider assessment of child understanding $(M=0.04, S D=0.298)$. Due to the low frequency of these variables, parent and child questions were combined into family questions to provider (Family Q.). Similarly, both provider assessment variables were combined into provider assessment of family understanding (Assess F.). AAP education sessions varied in length, lasting as short as 92 seconds and as long as 11 minutes $(M=186.11$ seconds, $M d n=146$ seconds $)$. The number of words spoken during the education session also varied dramatically $(M=471.99, S D=320.35)$, likely due mostly to variation in provider words spoken $(M=441.27, S D=265.63)$. Speech was consistently limited for parents $(M$ number of words $=27.09, S D=53.58)$ and children $(M$ number of words $=3.62, S D=13.43)$. A Pearson correlation matrix amongst parent and child communication variables and AKI total scores is displayed in Table 3. No communication variables evaluated in the study were found to be significantly $(p<.05)$ correlated with parent or child AKI scores.

To determine potential covariates for regression models, correlations also were calculated between AKI scores and child age, type of AAP, and time (in years) since diagnosis. Child age was significantly and positively correlated with child AKI total score $[r(41)=.373, p=.02]$, but not with parent AKI total score $[r(41)=.15, p=.34]$. Being assigned to the WAAP group was significantly associated with having a lower child AKI total score $[r(41)=-.473, p=.002]$ but 
there was no significant association for parent AKI total score $[r(41)=.03, p=.85]$. Finally, children having been diagnosed with asthma for a longer period of time had significantly higher child AKI total scores $[r(41)=.344, p=.03]$; time since diagnosis, however, was not significantly related to parent AKI scores $[r(41)=.09, p=.58]$.

\section{Aim 1 - Regression Analyses}

Regression analyses investigating child AKI total scores included the age of the child and time since asthma diagnosis as covariates (Models 1B, 1D, 1F). Type of AAP was not considered as a covariate for Aim 1 analyses because it was not significantly correlated with any of the predictor variables being examined. These variables were not significantly related to parent AKI total scores and thus not included as covariates where parent AKI score was the primary outcome variable (Models 1A, 1C, 1E). As a result of the combined family variables for parent/child questions and provider assessment of parent/child understanding being created to account for low frequency, models were modified to include the combined family variables.

Model 1A. A multiple linear regression was used to predict parent AKI total scores based on total number of provider questions posed to the parent, total number of provider directive statements posed to the parent, and provider assessment of family understanding. A nonsignificant regression equation was found $[F(3,37)=1.53, p=.22]$, with an $\mathrm{R}^{2}$ of .11 . Provider questions to parent $(\mathrm{B}=.12, p=.11)$, provider directive statements to parent $(\mathrm{B}=-.01, p=.87)$, and provider assessment of family understanding $(\mathrm{B}=-1.95, p=.06)$ were all non-significant contributors to the model.

Model 1B. A sequential multiple regression equation predicting child AKI total scores based on total number of provider questions posed to the child, total number of provider directive statements posed to the child, and provider assessment of family understanding was calculated. 
On the first step, child age and time since asthma diagnosis were entered (as covariates). On the second step, all of the remaining predictors were entered simultaneously, resulting in a significant change in $\mathrm{R}^{2}, F(2,38)=4.00, p=.03$. A non-significant regression equation was found for the full model $[F(5,35)=1.50, p=.22]$, with an $\mathrm{R}^{2}$ of .18 . Each of the following variables did not significantly contribute to the model: Provider questions to child $(\mathrm{B}=.04, p=$ $.88)$, provider directive statements to child $(\mathrm{B}=.02, p=.84)$, and provider assessment of family understanding $(\mathrm{B}=-.14, p=.92)$.

Model 1C. The total number of family questions posed to the provider was used to predict parent AKI total scores in a simple linear regression analysis. Results were not significant: $F(1,39)=$ $.776, p=.38 ; \mathrm{R}^{2}=.02$. Family question to the provider $(\mathrm{B}=-.15, p=.38)$ did not contribute significantly to the model.

Model 1D. To predict child AKI total scores based on total number of family questions posed to the provider, a sequential linear regression was performed. On the first step, child age and time since asthma diagnosis were entered as covariates. On the second step, all of the remaining predictors were entered simultaneously, resulting in a significant change in $\mathrm{R}^{2}, F(2,38)=3.998$, $p=.03$. Results for the full model yielded a non-significant regression equation $[F(3,37)=2.67$, $\left.p=.06 ; \mathrm{R}^{2}=.18\right]$. Family questions to the provider $(\mathrm{B}=-.08, p=.68)$ did not contribute significantly to the model.

Model 1E. A multiple linear regression was calculated to predict parent AKI total scores using total number of provider questions posed to the parent, total number of family questions posed to the provider, total number of provider directive statements posed to the parent, and provider assessment of family understanding as predictors. The resulting regression equation was found to be non-significant $[F(4,36)=1.13, p=.36]$, with an $\mathrm{R}^{2}$ of .11 . Provider questions to parent $(\mathrm{B}=$ 
$.11, p=.13)$, provider directive to parent $(\mathrm{B}=-.003, p=.97)$, family questions to provider $(\mathrm{B}=-$ $.05, p=.84)$, and provider assessment of family understanding $(\mathrm{B}=-1.78, p=.19)$ were all nonsignificant contributors to the model.

Model 1F. To predict child AKI total scores, a sequential multiple regression analysis was conducted with total number of provider questions posed to the child, total number of family questions posed to the provider, total number of provider directive statements posed to the child, and provider assessment of family understanding as predictors. On the first step, child age and time since diagnosis were entered. On the second step, all of the remaining predictors were entered simultaneously, resulting in a significant change in $\mathrm{R}^{2}, F(2,38)=4.00, p=.03$. Results for this equation were not significant: $F(6,34)=1.40, p=.24 ; \mathrm{R}^{2}=.20$. Provider questions to child $(\mathrm{B}=.16, p=.61)$, provider directive statements to child $(\mathrm{B}=.04, p=.63)$, family questions to provider $(\mathrm{B}=-.32, p=.34)$, and provider assessment of family understanding $(\mathrm{B}=.65, p=$ .69) were all non-significant contributors to the model.

\section{Aim 2 - Mediation Models}

Two parallel mediation analyses were conducted, evaluating the role of provider-family communication variables as potential mediators in the relation between AAP group type and AKI total scores for the relevant individual. Evidence for mediation is concluded if the $95 \%$ confidence interval (CI) for the indirect effect does not contain zero. Figure 3 details the results of Model 2A, while Figure 4 details the results of Model 2B.

Model 2A. An analysis of direct and indirect effects found that there was no significant indirect effect of any of the potential parent/family communication mediators (provider questions posed to the parent, family questions posed to the provider, provider directive statements to the parent, 
or provider assessment of family understanding), nor was there a significant direct effect observed within this model (see Figure 3).

Model 2B. Similar to Model 2A, results yielded no significant indirect effects of any of the potential child/family communication mediators (provider questions posed to the child, family questions posed to the provider, provider directive statements to the child, or provider assessment of family understanding) (see Figure 4). Additionally, there was no significant direct effect observed within this model.

\section{Discussion}

Asthma action plans (AAP) represent an easily referenceable treatment plan generated by asthma care providers to enable their patients to effectively manage asthma symptoms on a dayto-day basis. The AAP also has the potential to expand, or at the very least maintain, the patient's and family's knowledge regarding asthma care procedures. The overarching project, from which this study is drawn, sought to develop and evaluate a pictorial asthma action plan format that is intended to be easier for children and families to comprehend and that more readily engages them in their asthma care education.

The aim of the current study was to evaluate how provider-family communication, such as the number of questions posed by the provider to the family, during the initial review of the child's prescribed AAP contributes to both the pediatric patient's and caregiver's knowledge of the patient's treatment plan through both multiple linear regression analyses and mediation models. In the multiple linear regression analyses, patient and caregiver communication behaviors were modeled to evaluate their contribution to the observed outcome variable of interest, the parent's or child's understanding of the child's asthma treatment regimen as measured in a semi-structured treatment recall interview (i.e., AKI total score). Subsequently, 
communication variables were included in a parallel mediation model as potential mediators explaining the relation between AAP type (written versus pictorial) and AKI total score.

Unfortunately, across all analyses, the communication variables and type of AAP were not significantly predictive of AKI outcome variables. It may be the case that these results were influenced by the relatively low frequency of certain communication variables, such as parent or child questions to the provider. Many of the transcripts for education sessions revealed that both pediatric patients and their caregivers had relatively little input or verbal engagement with providers, even when the opportunity to do so was clearly given by providers. Similarly, providers tended to use directive statements with parents and children more frequently than they asked questions (e.g., to assess each family's understanding of how to manage the child's asthma). This limited variance, combined with the relatively small sample size, may have resulted in insufficient power to detect significant relations. Moreover, no evidence of these communication behaviors as mediators in the relation between AAP group type and the AKI total scores of the patient and their caregiver was observed. The previously noted limitations regarding the communication variables likely played a role in these null findings as well. While there was a significant Pearson correlation observed between AAP group type and child AKI total score, such that children in the PAAP group had better knowledge, the effect lost significance within the mediation model. This may have been due to small, non-significant indirect effects.

Despite non-significant regression models, several significant correlations amongst our variables provide interesting insights. One of the first, which was previously noted, is the significant correlation between AAP groups and child AKI scores. The fact that having a WAAP was significantly associated with a lower child AKI total score lends credence to the idea that 
pictorial AAPs indeed may be easier for children to comprehend. This correlation is perhaps even more notable given that the average age of participants in the study falls within early adolescence, where children are both growing more directly involved in managing their asthma and less impacted by general literacy concerns (Barton et al., 2002). Similarly, the significant positive correlation between child age and child AKI score, as well as time since diagnosis and child AKI score, hold consistent with previous literature (Barton et al., 2002). Barton et al. (2002) evaluated the impact of familial factors on adolescent asthma knowledge, in general, and only the age of the adolescent and knowledge of the father came out as significant predictors. The sample was considerably larger than ours and consisted solely of adolescents, aged 10-24 ( $n$ $=86)$, and caregivers $(n=46)$. This study examined more general knowledge of asthma, compared to the current study which assessed knowledge of the patient-specific treatment plan. This might result in the knowledge measurement in the current study being more relevant to asthma management specifically. Finally, parent and child AKI scores were significantly and positively correlated, which may lend evidence to the idea that parents and children receiving provider education at the same time learn or maintain treatment information at a commensurate rate. The resulting implication is that parents can serve as an additional source of information for their children to learn about managing their asthma in addition to their asthma care providers. A particular strength of the current study relates to the rigor of the behavioral coding conducted to assess communication behaviors from the providers, patients, and caregivers involved in AAP education sessions. A range of communication behaviors were considered in this project that had not been considered within any single previous study (Sleath et al., 2012; Sleath et al., 2011). Sleath et al. (2012) primarily focused on both child and provider questions regarding daily controller medications, while Sleath et al. (2011) focused on factors (parent and 
child questions regarding medications, provider seeking child input on care, etc.) involved in parent-child decision-making. Each of these studies had a slightly narrower focus, and findings may be less widely applicable as a result. Given the nature of the data being analyzed in the current study, an extensive codebook was developed. As a result, inter-rater reliability between coders was quite good, despite the breadth of communication behaviors being measured.

Additionally, the consistency and specificity of the procedure used during data collection served to ensure that there was very minimal missing data observed. In particular, the Asthma Knowledge Interview (AKI) was developed for use in this study and integrates both quantitative and qualitative items to provide a more wholistic picture of the participant's knowledge of their own specific asthma care. While the reliability between coders on the qualitative portion was a strength, the weaker reliability across items on the overall knowledge (AKI) measure make it a relative limitation of the project as well. In future studies, evaluating these quantitative and qualitative components separately may serve to improve the reliability of the measure(s) used.

Nevertheless, the current research had several limitations that impact the interpretation and utility of study findings. First, AAP education sessions were audio-recorded rather than video-recorded, which may have introduced uncertainty into coders' attempts to categorize some of the communication behavior as being directed towards one person or another. Second, the number of providers participating in the study was limited to two in total, which might contribute to the limited variability in provider communication behavior observed. Each provider was aware of the purpose of the study, though they were given limited instructions as to how to conduct education sessions beyond conveying the information present on the plan. These providers were from different specialties (pediatric allergy vs. pediatric pulmonology), with differing perspectives relating to prescribed care for their patients. These differences also 
extended to their approach to asthma education. While each provider consistently covered core aspects of the AAP, dialogue with patients was variable between patients for both providers. In some transcripts, providers conducted a two-way dialogue with patients about their asthma and their AAP, while others were structured by providers as more of a one-way informational session on the content of the child's AAP, involving limited family input or assessment of family understanding. On a related note, some education sessions were conducted independently of the rest of the visit, while others were integrated into feedback on test results or instruction on device technique. Also, our relatively small sample size of 45 participants likely resulted in weak or insufficient statistical power coupled with the low variability in both the communication predictor variables and knowledge outcome variable. The incidence of prior vs. new diagnosis in the sample may also be another consideration worth noting. While no participants in the sample had previously received an AAP, the overwhelming majority had been previously diagnosed with asthma and likely received some form of asthma education on one or more occasions. Additionally, they had experience managing their asthma. As a result, there was likely previous knowledge of asthma management that carried over to their new plans and could have influenced the variables of interest, including family communication variables (i.e., patients with new diagnoses potentially asking more questions). In future studies, it may be beneficial to have a truly naïve sample of participants who are exclusively new diagnoses in order to avoid this influence.

In sum, based on the results of the study, we found a significant correlation between the type of AAP given to families and their ability to recall treatment information. In addition, the age of the child and the time elapsed since they were diagnosed with asthma played a role in their knowledge, indicating that the child's developmental level and past experiences are likely 
worthwhile considerations for providers and other clinicians. Future research, based on the findings of the current study, should seek to expand the sample population to include not only a larger sample of study participants, but also larger number of asthma care providers who also range in their expertise (e.g., allergists, pulmonologists, primary care) to create a more robust representation of the communication that occurs between providers and their pediatric patients. Based on previous research (Nobile \& Drotar, 2003), there can be substantial variability between pediatric providers and their style of communication, but communication training often results in more positive communication behaviors, including assessment of psychosocial factors. Given the variance in approach and length of education observed within the current study, communication training centering around use of the pictorial asthma action plan (PAAP) as a semi-structured education tool may facilitate dialogue between providers and families. The developmental level of the patient often impacts the degree of asthma care responsibility they hold, and providers modulating asthma care education based on this factor is likely an important consideration. As noted previously, other positive communication behaviors to be considered include avoidance of jargon or inappropriate scientific language and adapting speech to suit the patient's developmental level (Sleath et al., 2012).Thus, systematically manipulating the type of communication being received (treatment-as-usual vs. providers with communication training) in conjunction with type of AAP in future research may be useful in identifying strategies to optimize patient and family understanding of asthma care. Indeed, in reviewing the literature on provider-patient communication, Ha and Longnecker (2010) found that communication training was beneficial in not only developing providers' communication skills, but also in maintaining these skills over time. Given the role of parents in providing both asthma education and maintenance between clinic visits, it is important for providers foster this relationship by 
promoting family communication during visits and ensuring that all of the family members involved in care receive adequate education (Divertie, 2002). Overall, the results of the current study suggest that it is important to structure provider communication and to encourage family engagement and communication during asthma education to facilitate good understanding of asthma care treatment plans. 


\section{References}

Adams, R. J., Boath, K., Homan, S., Campbell, D. A., \& Ruffin, R. E. (2001). A randomized trial of peak-flow and symptom-based action plans in adults with moderate-to-severe asthma.

Respirology, 6(4), 297-304. https://doi.org/10.1046/j.1440-1843.2001.00350.x

Ahmad, S. \& Ismail, N.E. (2015). Stigma in the lives of asthma patients: A review from the literature. International Journal of Pharmacy and Pharmaceutical Sciences, 7(7), 40-46.

Barton, C., Abramson, M., Aroni, R., Stewart, K., Thien, F., \& Sawyer, S. (2002). What determines knowledge of asthma among young people and their families? Journal of Asthma, 39(8), 701709. https://doi.org/10.1081/JAS-120015793

Becker, T. D., Lin, H. C., \& Miller, V. A. (2018). A pilot study of observed physician - parent - child communication and child satisfaction in a gastroenterology clinic. Patient Preference and Adherence, 12, 1327-1335.

Bhogal, S., Zemek, R., \& Ducharme, F. (2007). Cochrane review: Written action plans for asthma in children. Evidence-Based Child Health: A Cochrane Review Journal, 2(2), 553-603. https://doi.org/10.1002/ebch.131

Bombard, Y., Baker, G. R., Orlando, E., Fancott, C., Bhatia, P., Casalino, S., Onate, K., Denis, J.L., \& Pomey, M. P. (2018). Engaging patients to improve quality of care: A systematic review. Implementation Science, 13(98), 1-22. https://doi.org/10.1186/s13012-018-0784-z

Butz, A. M., Walker, J., Land, C. L., \& Vibbert, C. (2009). Improving asthma communication in highrisk children. Journal of Asthma, 44(9), 739-745. https://doi.org/10.1080/02770900701595683

Cabana, M. D., Slish, K. K., Evans, D., Mellins, R. B., Brown, R. W., Lin, X., Kaciroti, N. \& Clark, N. M. (2014). Impact of physician asthma care education on patient outcomes. Health Education and Behavior, 41(5), 509-517. https://doi.org/10.1177/1090198114547510 
Carpenter, D. M., Ayala, G. X., Williams, D. M., Yeatts, K. B., Davis, S., \& Sleath, B. (2013). The relationship between patient-provider communication and quality of life for children with asthma and their caregivers. Journal of Asthma, 50(7), 791-798.

https://doi.org/10.3109/02770903.2013.808347

Casey, D., O’Hara, M. C., Dinneen, S. F., Byrne, M., \& Hynes, L. (2015). 'It makes a difference, coming here': A qualitative exploration of clinic attendance among young adults with type 1 diabetes. British Journal of Health Psychology, 20(4), 842-858. https://doi.org/10.1111/bjhp.12145

Center for Disease Control - National Center for Health Statistics (2020, March 24). Most Recent Asthma Data. https://www.cdc.gov/asthma/most_recent_national_asthma_data.htm

Davis, T., Bocchini, J., Fredrickson, D., Arnold, C., Mayeaux, E., Murphy, P., Jackson, R., Hanna, N. \& Paterson, M. (1996). Parent comprehension of polio vaccine information pamphlets. Pediatrics, 97(6), 804-810.

Denham, S. A., Meyer, M. G., Toborg, M. A., \& Mande, M. J. (2004). Providing health education to Appalachia populations. Holistic Nursing Practice, 18(6), 293-301. https://doi.org/10.1097/00004650-200411000-00005

Diette, G.B., \& Rand, C. (2007). The contributing role of health-care communication to health disparities for minority patients with asthma. Chest, 132(5), 802S - 809S. https://doi.org/10.1378/chest.07-1909

Divertie, V. (2002). Strategies to promote medication adherence in children with asthma. The American Journal of Maternal/Child Nursing, 27(1), 10-18 
Douthit, N., Kiv, S., Dwolatzky, T., \& Biswas, S. (2020). Exposing some important barriers to health care access in the rural USA. Public Health, 129(6), 611-620. https://doi.org/10.1016/j.puhe.2015.04.001

Duncan, C. L., Tanner, A., Mentrikoski, J., Wilson, N., \& Hogan, M.B. (May 2012). Physicianfamily communication and family recall of treatment plans in pediatric asthma. American Thoracic Society International Conference 2012, San Francisco, CA.

Fox, C., Wisniewski, A., Lipman, P. D., Harris, D. R., Frame, P., \& Solberg, L. I. (2014). Implementing asthma guidelines using practice facilitation and local learning collaboratives: A randomized controlled trial. Annals of Family Medicine, 12(3), 233-240. https://doi.org/10.1370/afm.1624.Olmsted

Gibson, P. G., \& Powell, H. (2004). Written action plans for asthma: An evidence-based review of the key components. Thorax, 59(2), 94-99. https://doi.org/10.1136/thorax.2003.011858

Global Initiative for Asthma (2020, April 3). Global Strategy for Asthma Management and Prevention, 2020. Retrieved May 30 ${ }^{\text {th }}$, 2020 from https://ginasthma.org/wpcontent/uploads/2020/06/GINA-2020-report_20_06_04-1-wms.pdf

Globe, G., Martin, M., Schatz, M., Wiklund, I., Lin, J., von Maltzahn, R., \& Mattera, M. S. (2015). Symptoms and markers of symptom severity in asthma-content validity of the asthma symptom diary. Health and Quality of Life Outcomes, 13(1), 1-9. https://doi.org/10.1186/s12955-015$\underline{0217-5}$

Ha, J.F., \& Longnecker, N. (2010). Doctor-patient communication: A review. The Ochsner Journal, $10,38-43$ 
Hayes, A. F. (2012). PROCESS: A versatile computational tool for observed variable mediation, moderation, and conditional process modeling. Retrieved from http://www.afhayes.com/ public/process2012.pdf

Hedman, L., Lindgren, B., Perzanowski, M., \& Rönmark, E. (2005). Agreement between parental and self-completed questionnaires about asthma in teenagers. Pediatric Allergy and Immunology, 16(2), 176-181. https://doi.org/10.1111/j.1399-3038.2005.00231.x

Horner, S. D., \& Brown, A. (2015). An exploration of parent-child dyadic asthma management influences on quality of life. Comprehensive Child and Adolescent Nursing, 38(2), 85-104. https://doi.org/10.3109/01460862.2015.1017668

Hynes, L., Byrne, M., Casey, D., Dinneen, S.F., \& O’Hara, M.C. (2015). 'It makes a difference, coming here': A qualitative exploration of clinic attendance among young adults with type 1 diabetes. British Journal of Health Psychology, 20(4), 842-858.

https://doi.org/10.1111/bjhp.12145

Hynes, L., Durkin, K., Williford, D. N., Smith, H., Skoner, D., Lilly, C., Kothari, V. D., McSharry, J., \& Duncan, C. L. (2019). Comparing written versus pictorial asthma action plans to improve asthma management and health outcomes among children and adolescents: Protocol of a pilot and feasibility randomized controlled trial. JMIR Research Protocols, 8(6), e11733. https://doi.org/10.2196/11733

Janssens, T., \& Ritz, T. (2013). Perceived triggers of asthma: Key to symptom perception and management. Clinical and Experimental Allergy, 43(9), 1000-1008. https://doi.org/10.1111/cea.12138 
Letz, K.L., Schlie, A.R., \& Smits, W.L. (2004). A randomized trial comparing peak expiratory flow versus symptom self-management plans for children with persistent asthma. Pediatric Asthma, Allergy \& Immunology, 17(3), 177-190.

Ludke, R. L., Obermiller, P. J., Jacobson Jr., C., Shaw, T., Wells, V. E. (2006). "Sometimes it's hard to figure:" The functional health literacy of Appalachians in a metropolitan area. Journal of Appalachian Studies, 12(1), 7-25.

McHugh, M. L. (2012). Interrater reliability: The kappa statistic. Biochemia medica, 22(3), 276-282.

McMullen, A., Yoos, H. L., Anson, E., Kitzmann, H., Halterman, J. S., \& Arcoleo, K. S. (2007). Asthma care of children in clinical practice: do parents report receiving appropriate education? Pediatric Nursing, 33(1), 37-44.

McQuaid, E. L., Koinis Mitchell, D., Walders, N., Nassau, J. H., Kopel, S. J., Klein, R. B., ... Fritz, G. K. (2007). Pediatric asthma morbidity: The importance of symptom perception and family response to symptoms. Journal of Pediatric Psychology, 32(2), 167-177. https://doi.org/10.1093/jpepsy/jsj112

Moss, J.L., Gilkey, M.B., Rimer, B.K. \& Brewer, N.T. (2016). Disparities in collaborative patientprovider communication about human papillomavirus (HPV) vaccination. Human Vaccines \& Immunotherapeutics, 12(6), 1476-1483, DOI: 10.1080/21645515.2015.1128601

National Heart, Lung, and Blood Institute, National Asthma Education and Prevention Program (2012, September 2). Expert Panel Report 3: Guidelines for the Diagnosis and Management of Asthma Full Report 2007. https://www.nhlbi.nih.gov/sites/default/files/media/docs/EPR3_Asthma_Full_Report_2007.pdf 
Nobile, C., Drotar, D. (2003). Research on the Quality of Parent-Provider Communication in Pediatric Care: Implications and Recommendations. Journal of Developmental \& Behavioral Pediatrics, 24(4), 279-290

Okelo, A. S. O., Butz, A. M., Sharma, R., Diette, G.B., Pitts, S. I., King, T.M., Linn, S.T., Reuben, M., Chelladurai, Y., \& Robinson, K.A. (2013). Interventions to Modify Health Care Provider Adherence to Asthma Guidelines: A Systematic Review. Pediatrics, 132(3), 517-534. https://doi.org/10.1542/peds.2013-0779

Partridge, M. R. (2004). Written asthma action plans. Thorax, 59(2), 87-88. https://doi.org/10.1136/thx.2003.016451

Patel, M.R., Valerio, M.A., Sanders, G., Thomas, L.J., \& Clark, N.M. (2012). Asthma Action Plans and Patient Satisfaction Among Women with Asthma. Chest, 142(5), 1143-1149. doi: 10.1378/chest.11-1700

Peterson-Sweeney, K., McMullen, A., Yoos, H. L., \& Kitzman, H. (2003). Parental perceptions of their child's asthma: management and medication use. Journal of pediatric health care: official publication of National Association of Pediatric Nurse Associates \& Practitioners, 17(3), 118125. https://doi.org/10.1067/mph.2003.31

Petsios, K., Priftis, K. N., Tsoumakas, C., Tsanakas, J. N., Galanis, P., \& Antonogeorgos, G. (2011). Level of parent - asthmatic child agreement on health-related quality of life. Journal of Asthma, 48, 286-297. https://doi.org/10.3109/02770903.2011.555031

Ring, N., Jepson, R., Hoskins, G., Wilson, C., Pinnock, H., Sheikh, A., \& Wyke, S. (2011). Understanding what helps or hinders asthma action plan use: A systematic review and synthesis of the qualitative literature. Patient Education and Counseling, 85(2), e131-e143. https://doi.org/10.1016/J.PEC.2011.01.025 
Silva, N., Crespo, C., Carona, C., Bullinger, M., \& Canavarro, M. C. (2015). Why the (dis)agreement? Family context and child-parent perspectives on health-related quality of life and psychological problems in paediatric asthma. Child: Care, Health and Development, 41(1), 112-121. https://doi.org/10.1111/cch.12147

Sleath, B. L., Carpenter, D. M., Sayner, R., Ayala, G. X., Williams, D., Davis, S., Tudor, G. \& Yeatts, K. (2011). Child and caregiver involvement and shared decision-making during asthma pediatric visits. Journal of Asthma, 48, 1022-1031. https://doi.org/10.3109/02770903.2011.626482

Sleath, B., Carpenter, D. M., Ayala, G. X., Williams, D., Davis, S., Tudor, G., Yeatts, K. \& Gillette, C. (2012). Communication during pediatric asthma visits and child asthma medication device technique 1 month later. Journal of Asthma, 49(9), 918-925. https://doi.org/10.3109/02770903.2012.719250

Sonney, J., Segrin, C., \& Kolstad, T. (2019). Parent- and child-reported asthma responsibility in school-age children: Examining agreement, disagreement, and family functioning. Journal of Pediatric Health Care, 33(4), 386-393. https://doi.org/10.1016/j.pedhc.2018.11.005

Stewart, M., Masuda, J. R., Letourneau, N., Anderson, S., \& McGhan, S. (2011). "I want to meet other kids like me:" Support needs of children with asthma and allergies. Comprehensive Child and Adolescent Nursing, 34(2), 62-78. https://doi.org/10.3109/01460862.2011.572638

Turner, T., Cull, W. L., Bayldon, B., Klass, P., Sanders, L. M., Frintner, M. P., Abrams, M.P. \& Dreyer, B. (2009). Pediatricians and health literacy: Descriptive results from a national survey. Pediatrics, 124(Supplement 3), S299-S305. https://doi.org/10.1542/peds.2009-1162F

U.S. Census Bureau (2019). QuickFacts: West Virginia. Retrieved from https://www.census.gov/quickfacts/WV 
Valenzuela, J. M., \& Smith, L. (2016). Topical review: Provider-patient interactions: An important consideration for racial/ethnic health disparities in youth. Journal of Pediatric Psychology, 41(4), 473-480. https://doi.org/10.1093/jpepsy/jsv086

Waldecker, A., Malpass, A., King, A., \& Ridd, M. J. (2018). Written action plans for children with long- term conditions: A systematic review and synthesis of qualitative data. Health Expectations, 21, 585-596. https://doi.org/10.1111/hex.12643

Yin, H. S., Gupta, R. S., Tomopoulos, S., Wolf, M. S., Mendelsohn, A. L., Antler, L., Sanchez, D.C., Lau, C.H. \& Dreyer, B. P. (2013). Readability, suitability, and characteristics of asthma action plans: Examination of factors that may impair understanding. Pediatrics, 131(1), 117-126. https://doi.org/10.1542/peds.2012-0612

Yin, H. S., Gupta, R. S., Mendelsohn, A. L., Dreyer, B., Schaick, L. Van, Brown, C. R., Encalada, K., Sanchez, D.C., Warren, C.M. \& Tomopoulos, S. (2017). Use of a low-literacy written action plan to improve parent understanding of pediatric asthma management: A randomized controlled study. Journal of Asthma, 54(9), 919-929. https://doi.org/10.1080/02770903.2016.1277542 
Table 1. Descriptive Statistics for Study Variables

\begin{tabular}{lcccc}
\hline Variable & $N$ & Min. & Max. & Mean (SD) \\
\hline Child Age & 45 & 8 & 17 & $11.8(2.8)$ \\
Provider Question to Parent & 45 & 0 & 31 & $3.6(7.2)$ \\
Provider Question to Child & 45 & 0 & 11 & $1.6(2.3)$ \\
Family Question to Provider & 45 & 0 & 13 & $0.9(2.3)$ \\
Provider Directive to Parent & 45 & 0 & 32 & $6.5(8.6)$ \\
Provider Directive to Child & 45 & 0 & 36 & $7.0(7.0)$ \\
Assessment of Family Understanding & 45 & 0 & 2 & $0.1(.4)$ \\
Provider Talk $^{\mathrm{b}}$ & 45 & 178 & 1272 & $441.3(265.6)$ \\
Parent Talk $^{\mathrm{b}}$ & 45 & 0 & 283 & $27.1(53.6)$ \\
Child Talk $^{\mathrm{b}}$ & 45 & 0 & 90 & $3.6(13.4)$ \\
Total Talk $^{\mathrm{b}}$ & 45 & 179 & 1553 & $472.0(320.4)$ \\
Time Since Diagnosis $^{\mathrm{a}}$ & 45 & 4 & 15 & $9.7(4.7)$ \\
Parent AKI Total Score $^{\mathrm{a}}$ & 41 & 1 & 15 & $8.5(2.5)^{\mathrm{a}}$ \\
Child AKI Total Score $^{\mathrm{a}}$ & 41 & 0 & 17 & $5.3(3.0)^{\mathrm{a}}$ \\
\hline
\end{tabular}

${ }^{\text {a }}$ AKI Total Scores have a possible range of $0-16$.

${ }^{\mathrm{b}}$ Provider Talk $=$ total number of words spoken by provider; Parent Talk $=$ total number of words spoken by parent; Child Talk = total number of words spoken by child; Total Talk = total number of words spoken by all individuals. 


\section{Table 2. List of Variable Definitions}

\section{Frequency Variables}

All variables coded below are only in relation to asthma or allergy. Thus, any item that pertains to other topics (e.g., weather that day, phone contact information, insurance) will not be included in the frequency count.

\begin{tabular}{|c|c|}
\hline Label & Definition \\
\hline ProvQP & $\begin{array}{l}\text { Provider question (or statement in question form) posed to parent } \\
\text { - Examples: } \\
\text { ○ Tell me what you know about asthma. } \\
\text { ○ Is your child bothered by having to use an inhaler? } \\
\text { Note: In addition, separately tally the frequency of these } \\
\text { questions/statements that are intended to assess the parent's } \\
\text { understanding of the child's asthma treatment plan. } \\
\text { - Examples: } \\
\text { O How many puffs should your child take each time? } \\
\text { Describe the steps you'd take when your son's asthma flare is } \\
\text { severe and won't respond to albuterol. }\end{array}$ \\
\hline ProvQC & $\begin{array}{l}\text { Provider question (or statement in question form) posed to child } \\
\text { - Examples: } \\
\text { ○ Do you ever feel chest tightness? } \\
\text { ○ How often are you having asthma attacks during your sports } \\
\text { practice? } \\
\text { Note: In addition, separately tally the frequency of these } \\
\text { questions/statements that are intended to assess the child's understanding } \\
\text { of the child's asthma treatment plan. } \\
\text { - Examples: } \\
\circ \text { When should you use your rescue inhaler, \{Child name }\} \text { ? } \\
\circ \quad\{\text { Child name }\} \text {, tell me how many times a day you should use } \\
\text { your controller inhaler. }\end{array}$ \\
\hline ParentQProv & $\begin{array}{l}\text { Parent question posed to provider } \\
\text { - Examples: } \\
\text { o Who do I call if my child can't breathe? } \\
\circ \text { How many puffs should my child take each day? }\end{array}$ \\
\hline ChildQProv & $\begin{array}{l}\text { Child question posed to provider } \\
\text { - Examples: } \\
\text { ○ How do I use my inhaler? } \\
\text { ○ Will taking my inhaler make me breathe better? }\end{array}$ \\
\hline ProvDirP $^{a}$ & $\begin{array}{l}\text { Provider directive statement or instruction made to parent } \\
\text { - Examples: } \\
\text { o You'll need to pick up the prescription from your pharmacy. }\end{array}$ \\
\hline
\end{tabular}




\begin{tabular}{|c|c|}
\hline & o You can have him use this inhaler when he is wheezing. \\
\hline ProvDirC $^{a}$ & $\begin{array}{l}\text { Provider directive statement or instruction made to child } \\
\text { - Example: } \\
\text { o Take one puff of your inhaler in the morning and at night. }\end{array}$ \\
\hline ProvDirA $^{\mathrm{a}}$ & $\begin{array}{l}\text { Provider directive statement or instruction with ambiguous target } \\
\text { - Example: } \\
\text { o We'll need to keep an eye out for any problems as they come up. } \\
\text { - If a directive statement/instruction is made that includes both the } \\
\text { parent and child, code as a directive for parent and for child } \\
\text { separately ("You and your mother need to keep an eye out for asthma } \\
\text { symptoms.") }\end{array}$ \\
\hline ProvAssessP & $\begin{array}{l}\text { Provider statement or question assessing parent understanding of } \\
\text { treatment knowledge } \\
\text { - Example: } \\
\quad \text { O When should your child take his rescue inhaler? } \\
\circ \text { Tell me when you should call the clinic regarding your } \\
\quad \text { child's asthma. }\end{array}$ \\
\hline ProvAssessC & $\begin{array}{l}\text { Provider statement or question assessing child understanding of } \\
\text { treatment knowledge } \\
\text { - Example: } \\
\circ \text { What is the difference between your rescue and controller } \\
\text { inhalers? } \\
\circ \quad \text { Now, tell me the difference between your controller inhaler } \\
\text { and your rescue inhaler. }\end{array}$ \\
\hline ProvAssessB/U & $\begin{array}{l}\text { Provider statement or question assessing understanding of treatment } \\
\text { knowledge for either: }(A) \text { Both parent and child, }(B) \text { Unclear target. }\end{array}$ \\
\hline
\end{tabular}

a Statement is defined as, "A word or series of words followed by punctuation (., !, ?, :) or a pause longer than two seconds."

\section{Count Variables}

The following variables are a function of word count, regardless of the content (i.e., asthmarelated or not):

\begin{tabular}{|l|l|}
\hline ProvTalk & Number of provider words spoken. \\
\hline CTalk & Number of child words spoken. \\
\hline PTalk & Number of caregiver words spoken. \\
\hline
\end{tabular}

Note: For word count, non-word utterances ("uh," "hmm," screaming, etc.) that cannot easily be defined should be excluded. Utterances with clear definitions (e.g., "mm-hmm," as an affirmative response) should be included. 
Table 3. Correlation Matrix

\begin{tabular}{|c|c|c|c|c|c|c|c|c|c|c|c|c|c|}
\hline Variable & 1 & 2 & 3 & 4 & 5 & 6 & 7 & 8 & 9 & 10 & 11 & 12 & 13 \\
\hline \multicolumn{14}{|l|}{ 1. Child Age } \\
\hline 2. Time Since Dx & $.484 * *$ & & & & & & & & & & & & \\
\hline 3. Provider Q.P. & .09 & .00 & & & & & & & & & & & \\
\hline 4. Provider Q.C. & .23 & .13 & $.67 * *$ & & & & & & & & & & \\
\hline 5. Family Q. & -.12 & -.01 & $.43 * *$ & $.64 * *$ & & & & & & & & & \\
\hline 6. Provider D.P. & -.09 & -.23 & $.60 * *$ & $.41 * *$ & $.60 * *$ & & & & & & & & \\
\hline 7. Provider D.C. & $.37 *$ & .22 & -.04 & $.47 * *$ & $.47 * *$ & -.21 & & & & & & & \\
\hline 8. Assess F. & .15 & .26 & $.55^{* *}$ & $.59 * *$ & $.70 * *$ & $.42 * *$ & $.38 * *$ & & & & & & \\
\hline 9. Provider Talk & .12 & -.15 & $.80 * *$ & $.61 * *$ & $.71 * *$ & $.83 * *$ & .08 & $.55^{* *}$ & & & & & \\
\hline 10. Parent Talk & .15 & -.03 & $.66^{* *}$ & $.73 * *$ & $.91 * *$ & $.74 * *$ & $.36^{*}$ & $.74 *$ & $.86^{* *}$ & & & & \\
\hline 11. Child Talk & .11 & .08 & .29 & $.67 * *$ & $.81 * *$ & $.49 * *$ & $.63 * *$ & $.67 * *$ & $.49 * *$ & $.77 * *$ & & & \\
\hline 12. Total Talk & .12 & -.12 & $.78 * *$ & $.65 * *$ & $.78 * *$ & $.83 * *$ & .15 & $.61 * *$ & $.99 * *$ & $.91 * *$ & $.58 * *$ & & \\
\hline 13. Parent AKI & .15 & .09 & .14 & -.02 & -.14 & .03 & -.12 & -.18 & .05 & -.13 & -.14 & .15 & \\
\hline 14. Child AKI & $.37 *$ & $.34 *$ & .14 & .14 & -.03 & -.02 & .18 & .11 & .08 & .04 & .08 & .07 & $.39 *$ \\
\hline
\end{tabular}

Note: Provider Q.P. = Provider Questions to Parent; Provider Q.C. = Provider Questions to Child; Family Q. = Family Questions to Provider; Provider D.P. = Provider Directive Statements to Parent; Provider D.C. = Provider Directive Statements to Child; Assess F. $=$ Provider Assessment of Family Understanding.

$*$ indicates $p<.05 . * *$ indicates $p<.01$. 


\section{Figure 1}

\section{Written Asthma Action Plan}

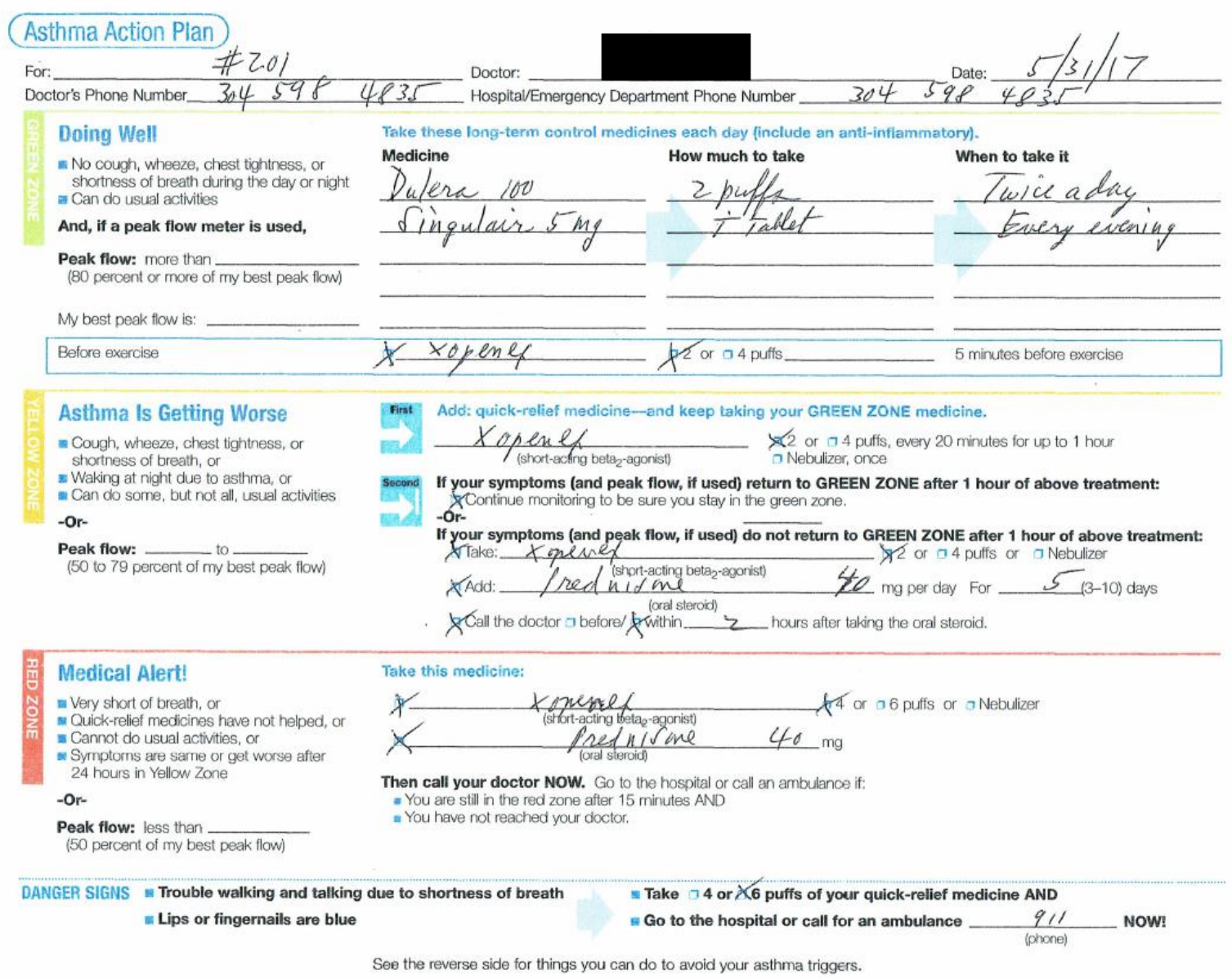

Note. Example of written asthma action plan (WAAP) used in the current study. 


\section{Figure 2}

\section{Pictorial Asthma Action Plan}

Asthma Action Plan - Patient Study \#101
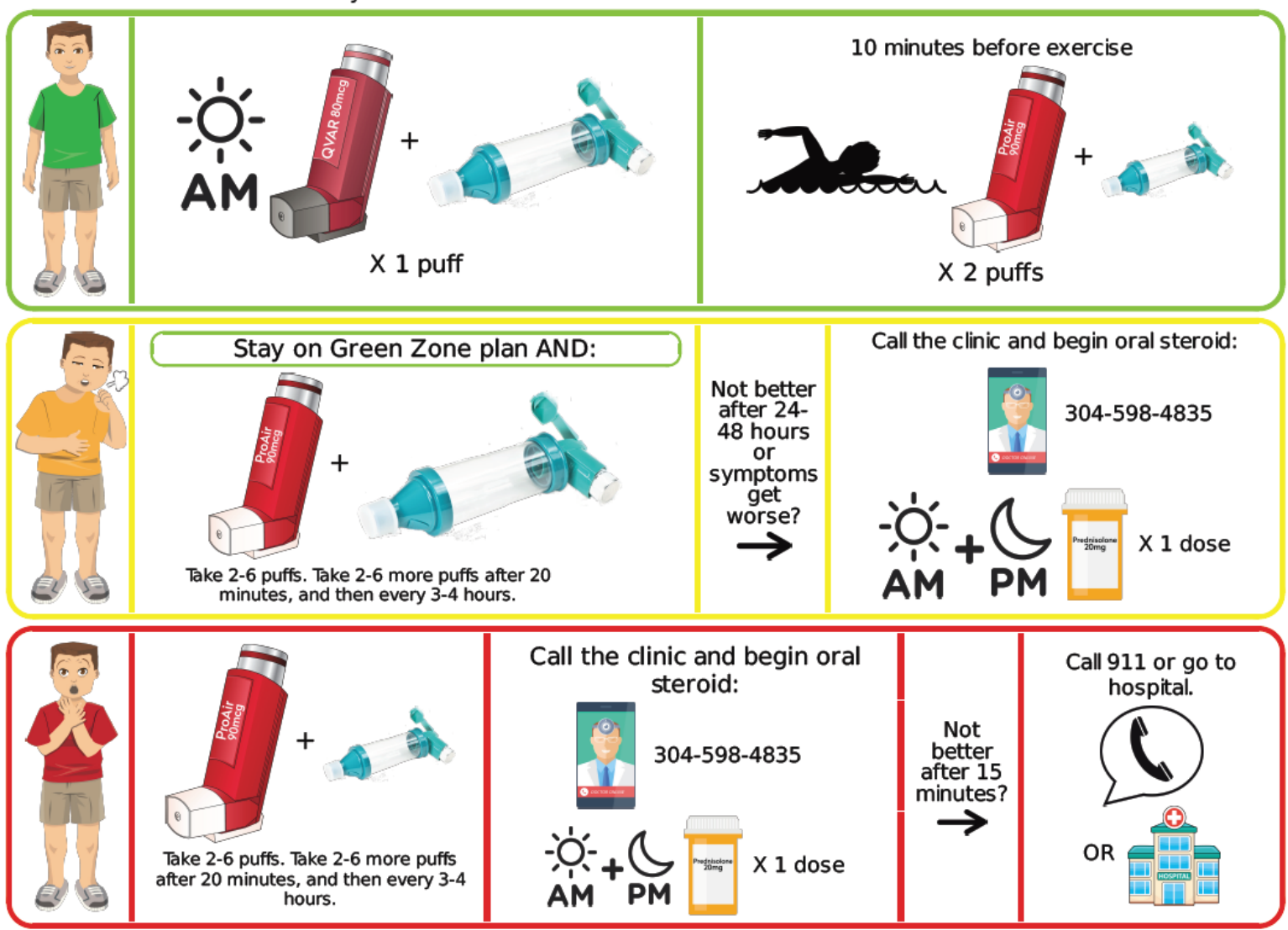

Note. Example of pictorial asthma action plan (PAAP) used in the current study. 


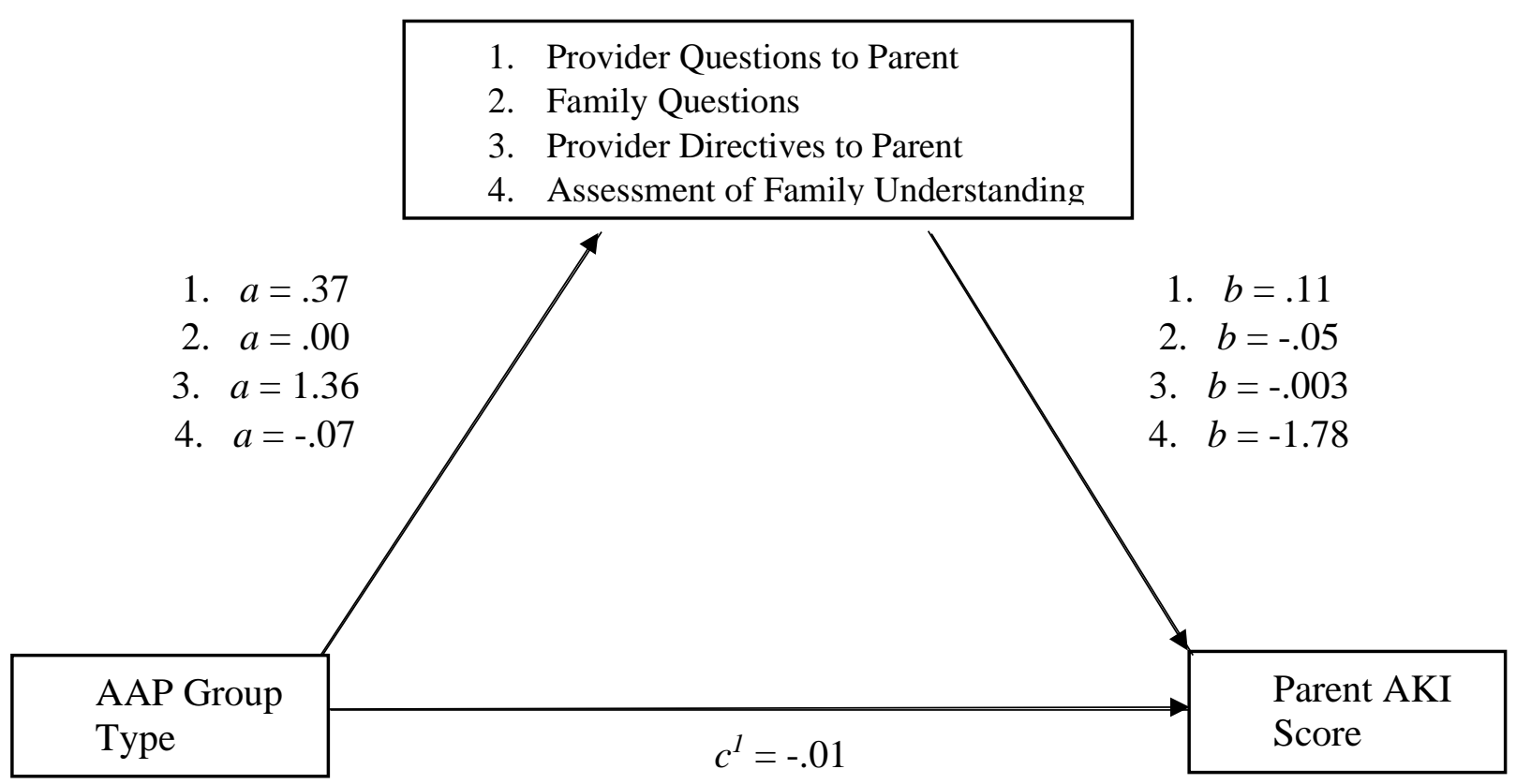

Figure 3. Parallel Mediation Model 2A. Mediation model testing communication variables as potential mediators in the relation of Asthma Action Plan (AAP) type (Pictorial vs. Written) predicting Parent Asthma Knowledge Interview (AKI) score. 


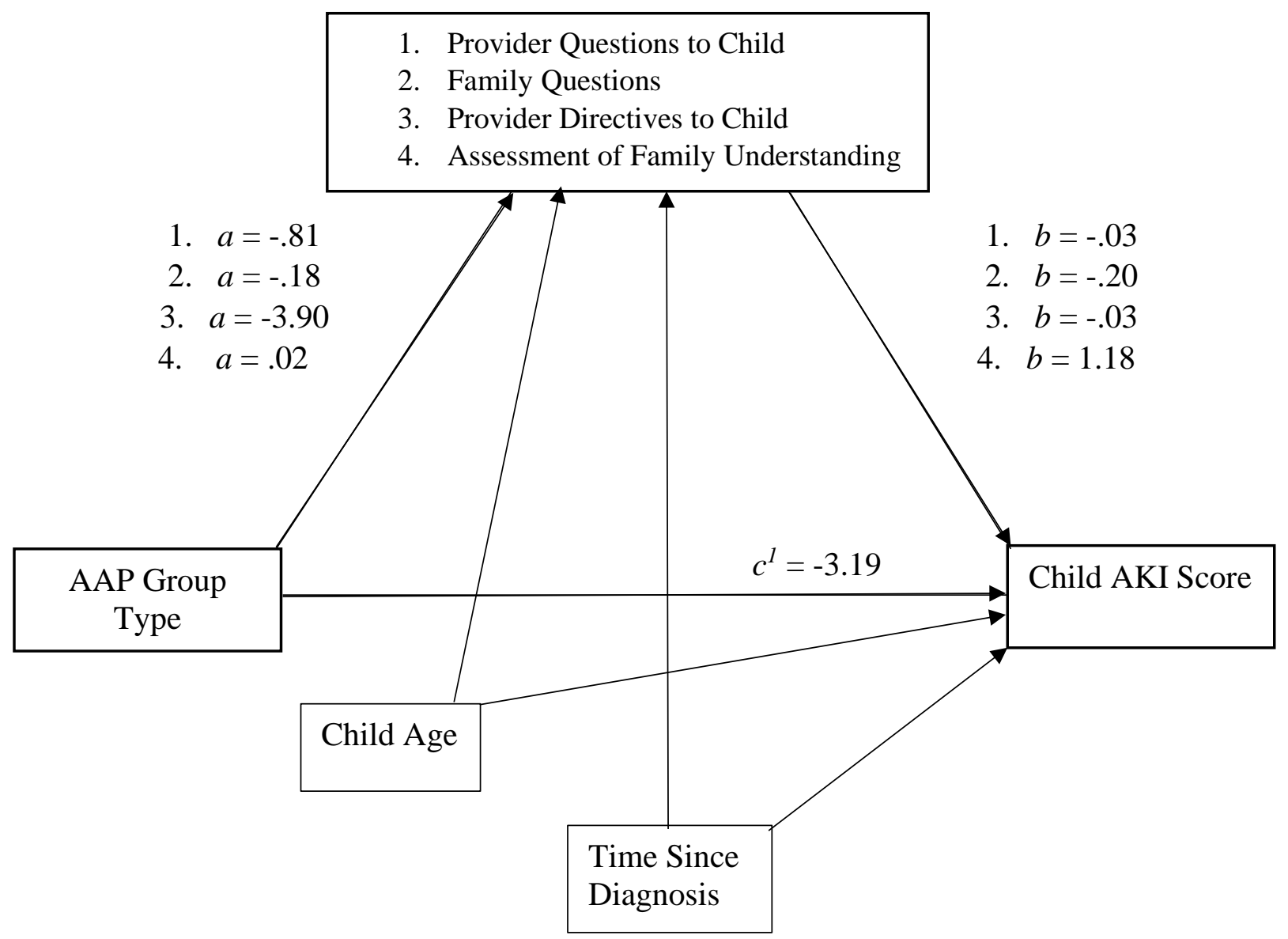

Figure 4. Parallel Mediation Model 2B. Mediation model testing communication variables as potential mediators in the relation of Asthma Action Plan (AAP) type (Pictorial vs. Written) predicting Child Asthma Knowledge Interview (AKI) score, while controlling for child age and time since diagnosis. 
Appendix A: Patient Information Form (PIF)

ID \#

TODAY'S DATE:

\section{PATIENT INFORMATION FORM}

Note: This form should be completed by PARENT/CAREGIVER, with the help of the patient. Please answer the following questions as well as you can. If you have any problems, please ask the researcher for some help.

\section{PATIENT INFORMATION:}

AGE:

DATE OF BIRTH:

SEX (circle): $\quad$ Male Female

RACE (circle): Caucasian African-American Asian-American Hispanic/Latino

Other (please specify):

GRADE:

1. Was your child diagnosed with asthma prior to this appointment?

드o __ Yes (At what age? ___

If YES, did your child previously receive a WRITTEN asthma action plan on what to do each day for asthma care, and how to respond to asthma symptoms? This plan may have included information on what to do in a green zone, yellow zone, and red zone.

No _ Yes

2. Does your child have any relatives (family members) with asthma?

No No Yes

If YES, please try to list ALL of them (mother, grandfather, cousin, etc.):

3. Does your child have any illnesses other than asthma?

No __ Yes (Please list:

4. Has your child received any kind of special education services for learning problems?

No __ Yes (In what grades?

Please describe your child's learning problems- 
5. What type of health insurance does your child have? Please list all types.

\section{FAMILY INFORMATION:}

What is your relationship to the patient (for example: mother, grandparent)?

What is YOUR age?

1. Please make a check in front of each family member that is CURRENTLY living in your child's home.

Biological Mother Adoptive or Step-Mother Brother (How many? Grandparent (How many? Other (list by relationship to shild)
Biological Father

Adoptive or Step-Father

Sister (How many?

\section{Please make a check in front of your marital status.}

Never Been Married / Single Married to other biological parent Living with boyfriend $/$ girlfriend

\section{Divorced/ Single}

Remarried to step-parent

Widowed (other biological parent is deceased)

For the rest of the questions on this page, please list/describe those people (typically, the parents) that PROVIDE FOR THE HOUSEHOLD (help to pay bills, buy food, buy clothes, etc.).

\begin{tabular}{|lll|}
\hline 1 & $=$ & 6th grade or less \\
2 & $=$ & 7 th, 8th, or 9th grade \\
3 & $=$ & Some high school (10th or 11th grade) \\
4 & $=$ & Graduate from high school \\
5 & $=$ & Some college (at least 1 year) or specialized training (example: Vocational) \\
6 & $=$ & Bachelor's degree, graduated from a 4-year college (UF, FSU, USF, etc.) \\
7 & $=$ & Master's degree, doctoral degree
\end{tabular}

3. Using the above scale in the box, please show the highest level of education completed by the people who PROVIDE for the CHILD (help pay bills, buy food, buy clothes). If the person listed is NOT the mother or father of the child, please write who this person is (for example: step-parent, grandparent) next to it.

Mother $=$ Father =

4. Please provide a job title \& description for the persons listed in Question \# 3. 
Mother (or other):

Father (or other):

5. Please check your total, annual family income level:

Less than $\$ 15,000$

$\$ 15,000-\$ 29,999$

$\$ 30,000-\$ 44,999$

$\$ 45,000-\$ 59,999$

$\$ 60,000-\$ 74,999$

$\$ 75,000$ and greater

6. What is your zip code? 
Appendix B: Asthma Knowledge Interview(s)

Form A

\section{ACTION PLAN KNOWLEDGE INTERVIEW - CHILD FORM}

Study Number:

Date:

Age of Child: $\quad$ Session \#: $\square$ Enrollment/Baseline $\square$ 3-months $\square$ 6-months

Directions to Interviewer: Ask the child the following questions verbatim. Circle the child's response regarding the identified zone for questions 1 to 7 . Write the child's verbatim response for their treatment plan in the space provided following questions 9 to 11 . Tick the box that describes how much the child glances at or reads from their AAP as they answer all questions. If the child does not provide all of the treatment plan details for any of the zones, you may make up to 2 queries, saying "Can you tell me more about your treatment plan in the X zone please?"' Write (Q) beside the responses each time you make a query.

Administration Instructions: "I'm going to ask you some questions about your new asthma action plan. You can look at the AAP any time, but please give me your own answers in your own words. For the first several questions, I will describe examples of asthma symptoms you might have and ask you to tell me what zone you would be in each time. For the second half of the survey, I'll ask you to tell me about the things you need to do to take care of your asthma in the green, yellow and red zones. Please stop me anytime to ask questions if you need to."

1. You come in from playing outside for an hour. You are NOT coughing or wheezing and seem to be breathing okay. What zone are you in?

Green $\quad$ Yellow $\quad$ Red

- Did not look at A.AP $\square \quad$ Looked at A.A.P briefly $\square \quad$ Looked at A.A.P > geveral geconds $\square$

2. You are playing ball at a friend's house. Your chest feels tight and you start to cough. You took your asthma medicine before going to your friend's house. What zone are you in?

Green $\quad$ Yellow $\quad$ Red

- Did not look at A.AP $\square \quad$ Looked at A.A.P briefly $\square \quad$ Looked at A.A.P > geveral geconds $\square$

3. You were riding your bike and started to wheeze just a little. You took one breathing treatment and now you feel better. What zone were you in when you decided to take this treatment?

Green $\quad$ Yellow $\quad$ Red

- Did not look at A.AP $\square \quad$ Looked at A.A.P briefly $\square \quad$ Looked at A.A.P > geveral geconds $\square$ 
Form A

4. You are coughing often. You took 3 rescue treatments and you still are coughing. What zone are you in?

Green $\quad$ Yellow $\quad$ Red

- Did not look at A.AP $\square \quad$ Looked at A.A.P briefly $\square \quad$ Looked at A.A.P > geveral geconds $\square$

5. You are allergic to rag weed and it is that time of the year when rag weed pollen is bad. You have had itchy eyes and a scratchy throat for several days. What zone are you in?

$$
\text { Green } \quad \text { Yellow } \quad \text { Red }
$$

- Did not look at A.AP $\square$ Looked at A.A.P briefly $\square \quad$ Looked at A.A.P > geveral geconds $\square$

6. After a night of good sleep, you wake up feeling well. You do not feel any chest tightness or wheezing and you have not been coughing. What zone are you in?

$$
\text { Green } \quad \text { Yellow } \quad \text { Red }
$$

- Did not look at A.AP $\square \quad$ Looked at A.A.P briefly $\square \quad$ Looked at A.A.P > geveral geconds $\square$

7. Your chest feels tight and you are wheezing. You have taken 2 breathing treatments and still do not feel better. What zone are you in?

$$
\text { Green } \quad \text { Yellow } \quad \text { Red }
$$

- Did not look at A.AP $\square \quad$ Looked at A.A.P briefly $\square \quad$ Looked at A.A.P > geveral geconds $\square$

8. Do you regularly take part in any activities (such as sports) for which you take albuterol beforehand?

YES No

9. Please describe in detail what you should do when you are in the GREEN zone of your asthma action plan. 
Form A

- Did not look at A.AP $\square \quad$ Looked at A.A.P briefly $\square \quad$ Looked at A.A.P > geveral geconds $\square$ Read action plan to provide answer $\square$

10. Now describe in detail what you should do when you are in the YELLOW zone of your asthma action plan.

- Looked at A.AP briefly? _ Looked at A.AP for several seconds?

Read action plan to provide answer Did not look at A.AP?

11. Finally, please describe in detail what you should do when you are in the RED zone of your asthma action plan.

- Did not look at A.AP $\square$ Looked at A.A.P briefly $\square \quad$ Looked at A.A.P > geveral geconds $\square$

Read action plan to provide answer $\square$ 
Form A

\section{ACTION PLAN KNOWLEDGE INTERVIEW-PARENT/CAREGIVER FORM}

Study Number:

Date:

Age of Child: $\quad$ Session \#: $\square$ Enrollment Baseline $\square$ 3-months $\square$ 6-months

Directions to Interviewer: Ask the parent the following questions verbatim. Circle the parent's response regarding the identified zone for questions 1 to 7 . Write the parent's verbatim response for their treatment plan in the space provided following questions 9 to 11 . Tick the box that describes how much the parent glances at or reads from their AAP as they answer all questions. If the parent does not provide all of the treatment plan details for any of the zones, you may make up to 2 queries, saying "Can you tell me more about your child's treatment plan in the X zone please?" Write (Q) beside the responses each time you make a query.

Administration Instructions: "I'm going to ask you some questions about your child's new asthma action plan. You can look at the AAP any time, but please give me your own answers in your own words. For the first several questions, I will describe examples of asthma symptoms your child might have and ask you to tell me what zone your child would be in each time. For the second half of the survey, I'll ask you to tell me about the things your child needs to do to take care of his/her asthma in the green, yellow and red zones. Please stop me anytime to ask questions if you need to."

1. Your child comes in from playing outside for an hour. He/she is NOT coughing or wheezing and seems to be breathing okay. What zone is your child in?

Green $\quad$ Yellow $\quad$ Red

- Did not look at A.AP $\square$ Looked at A.A.P briefly $\square$ Looked at A.A.P > geveral geconds $\square$

2. Your child is playing ball at a friend's house. He/she feels chest tightness and begins to cough. Your child took his/her asthma medicine before going to a friend's house. What zone is your child in?

Green $\quad$ Yellow $\quad$ Red

- Did not look at A.A.P $\square \quad$ Looked at A.A.P briefly $\square \quad$ Looked at A.A.P > geveral geconds $\square$

3. Your child was riding his/her bike and started to wheeze just a little. He/she took one breathing treatment and now feels better. What zone was your child in when he/she decided to take this treatment?
Green
Yellow
Red

- Did not look at A.AP $\square \quad$ Looked at A.A.P briefly $\square \quad$ Looked at A.A.P > geveral geconds $\square$ 
4. Your child is coughing often. He/she took 3 rescue treatments and is still coughing. What zone is your child in?

$$
\text { Green } \quad \text { Yellow } \quad \text { Red }
$$

- Did not look at A.AP $\square \quad$ Looked at A.A.P briefly $\square \quad$ Looked at A.A.P > geveral geconds $\square$

5. Your child is allergic to rag weed and it is that time of the year when rag weed pollen is bad. He/she has had itchy eyes and a scratchy throat for several days. What zone is your child in?

$$
\text { Green } \quad \text { Yellow } \quad \text { Red }
$$

- Did not look at A.AP $\square \quad$ Looked at A.A.P briefly $\square \quad$ Looked at A.A.P > geveral geconds $\square$

6. After a night of good sleep, your child wakes up feeling well. He/she does not feel any chest tightness or wheezing and has not been coughing. What zone is your child in?

Green Yellow Red

- Did not look at A.AP $\square$ Looked at A.A.P briefly $\square \quad$ Looked at A.A.P > geveral geconds $\square$

7. Your child has chest tightness and is wheezing. He/she has taken 2 breathing treatments and still does not feel better. What zone is your child in?

$$
\text { Green } \quad \text { Yellow } \quad \text { Red }
$$

- Did not look at A.AP $\square \quad$ Looked at A.A.P briefly $\square$ Looked at A.A.P > geveral geconds $\square$

1. Does your child regularly take part in any activities (such as sports) for which he or she takes albuterol beforehand?

YES No

2. Please describe in detail what your child should do when he/she is in the GREEN zone of his/her asthma action plan. 
Form A

\section{- Did not look at A.AP $\square$ Looked at A.A.P briefly $\square$ Looked at A.A.P > geveral geconds $\square$ \\ Read action plan to provide answer $\square$}

3. Now describe in detail what your child should do when he/she is in the YELLOW zone of his/her asthma action plan.

- Did not look at A.AP $\square$ Looked at A.A.P briefly $\square$ Looked at A.A.P > geveral geconds $\square$ Read action plan to provide answer $\square$

4. Finally, please describe in detail what your child should do when he/she is in the RED zone of his/her asthma action plan.

- Did not look at A.A.P $\square \quad$ Looked at A.A.P briefly $\square \quad$ Looked at A.A.P > geveral seconds $\square$ Read action plan to provide answer $\square$ 
Appendix C: Provider-Patient Communication Coding Sheet

Listen to the audiotape AGAIN to tally the frequency of the following information. For each SEPARATE piece of information, place a tally mark in the box to the right of its category. If you do NOT know how to classify a piece of information, DO NOT place a tally mark. Instead, record the statement VERBATIM in the space below.

\begin{tabular}{|c|c|}
\hline $\begin{array}{c}\text { Provider Question to Parent } \\
\text { (e.g., "Tell me what you know about asthma," } \\
\text { "Do you understand how to use your child's } \\
\text { nebulizer?") }\end{array}$ & \\
\hline $\begin{array}{c}\text { Provider Question to Child } \\
\text { (e.g., "Show me how you use your inhaler," } \\
\text { "Which medicine do you take twice a day?") }\end{array}$ & \\
\hline Parent Question to Provider & \\
\hline Child Question to Provider & \\
\hline $\begin{array}{l}\text { (e.g., "Do X," "Don't do X," "How to do } \\
\text { (...Cover your child's bed mattress \& pillow } \\
\text { with an allergen proof cover.") }\end{array}$ & \\
\hline
\end{tabular}




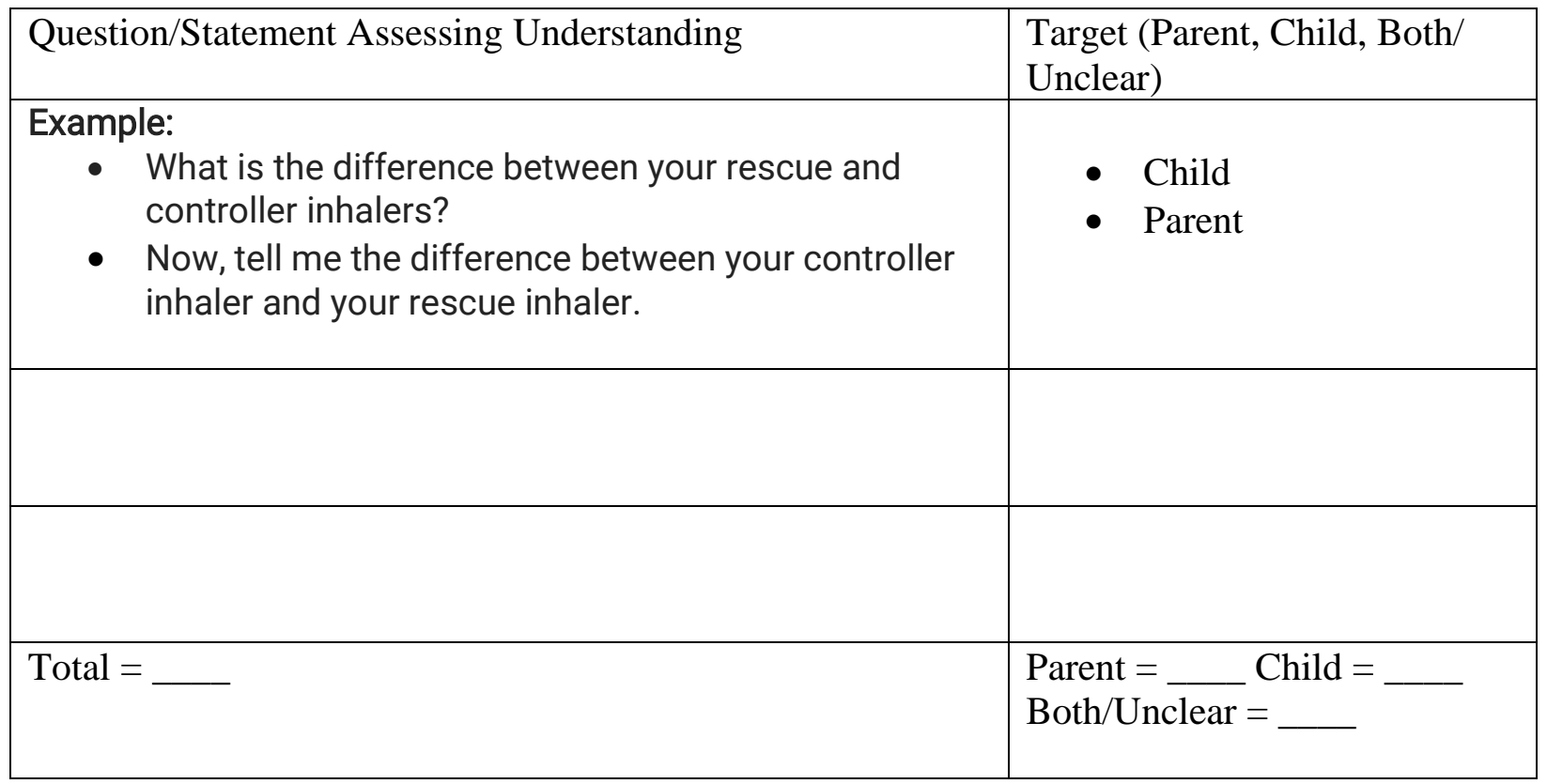

\begin{tabular}{|l|l|l|l|}
\hline Speaker & Word Count & Total Words & Ratio \\
\hline Provider & & & $/$ \\
\hline Child & & & $/$ \\
\hline Caregiver & & & $/$ \\
\hline
\end{tabular}

